\title{
Academic engagement: A review of the literature 2011-2019
}

\author{
Markus Perkmann $^{\mathrm{a}, *}$, Rossella Salandra ${ }^{\mathrm{b}}$, Valentina $\operatorname{Tartari}^{\mathrm{c}}{ }^{\mathrm{c}}$, Maureen McKelvey ${ }^{\mathrm{d}}$, Alan Hughes ${ }^{\mathrm{a}, \mathrm{e}}$ \\ a Imperial College Business School, South Kensington Campus, London SW7 2AZ, United Kingdom \\ ${ }^{\mathrm{b}}$ School of Management, University of Bath, Claverton Down Road, Bath BA2 7AY, United Kingdom \\ ${ }^{\mathrm{c}}$ Department of Strategy and Innovation, Copenhagen Business School, Kilevej 14A, Frederiksberg 2000, Denmark \\ ${ }^{\mathrm{d}}$ University of Gothenburg, School of Business, Law and Economics, Department of Economy and Society, Institute of Innovation and Entrepreneurship, P.O Box 610, \\ Gothenburg SE-405 30, Sweden \\ ${ }^{\mathrm{e}}$ Lancaster University Management School, Bailrigg, Lancaster W7LA1 4YX, United Kingdom
}

A R T I C L E IN F O

\section{Keywords:}

University-industry relations

Technology transfer

Academic entrepreneurship

Commercialisation

Collaborative research

Academic consulting

\begin{abstract}
A B S T R A C T
We provide a systematic review of the literature on academic engagement from 2011 onwards, which was the cut-off year of a previous review article published in Research Policy. Academic engagement refers to knowledge-related interactions of academic scientists with external organisations. It includes activities such as collaborative research with industry, contract research, consulting and informal ties. We consolidate what is known about the individual, organisational and institutional antecedents of academic engagement, and its consequences for research, commercialisation, and society at large. Our results suggest that individual characteristics associated with academic engagement include being scientifically productive, senior, male, locally trained, and commercially experienced. Academic engagement is also socially conditioned by peer effects and disciplinary characteristics. In terms of consequences, academic engagement is positively associated with academics' subsequent scientific productivity. We propose new areas of investigation where evidence remains inconclusive, including individual life cycle effects, the role of organisational contexts and incentives, cross-national comparisons, and the impact of academic engagement on the quality of subsequent research as well as the educational, commercial and society-wide impact.
\end{abstract}

\section{Introduction}

In 2013, as part of a wider team of authors, we published a review paper on academic engagement in this journal (Perkmann et al., 2013). Academic engagement refers to knowledge-related interactions by academic researchers with non-academic organisations, as distinct from teaching and commercialisation. These interactions include collaborative research, contract research and consulting as well as informal activities such as providing ad hoc advice and networking with practitioners. Academic engagement warrants attention as an important part of academics' portfolio of activities distinct from commercialisation and teaching.

Since our original review, academic engagement has continued to attract major interest from students of science and universities, and innovation more broadly. More than ever, it represents a focus of attention for universities and policy makers, as it is seen as a transmission mechanism for ensuring academic research has an impact on the economy and society (Bornmann, 2013; Martin, 2011). Compared to commercialisation - creating intellectual property and faculty entrepreneurship - academic engagement is practiced more widely across disciplines and is of greater economic significance for universities and companies (Cohen et al., 2002; Hughes and Kitson, 2012; Hughes et al., 2016).

Scholarly interest has closely tracked the relevance of the topic with a substantial increase in publications on academic engagement. The emerging body of research has remained relatively fragmented, particularly as authors have foregrounded some newly relevant aspects of academic engagement, such as the role of gender and geographic mobility. Moreover, the quest for facilitating a greater impact of science raises the question of what overall evidence we have on the consequences of academic engagement. Against this background, we intend to provide an update of our previous review, with a particular view to probing the robustness of its conclusions and to assess progress in meeting the challenges we identified.

To this purpose, we perform a systematic search for published articles using the same methodology as in the previous review and

\footnotetext{
* Corresponding author.

E-mail addresses: m.perkmann@imperial.ac.uk (M. Perkmann), r.salandra@bath.ac.uk (R. Salandra), vt.si@cbs.dk (V. Tartari), maureen.mckelvey@handels.gu.se (M. McKelvey), a.hughes@imperial.ac.uk, a.hughes8@lancaster.ac.uk (A. Hughes).
} 
analyse them using the same protocol. Given the recent volume of research, we focus on academic engagement only, rather than considering commercialisation. Our objective is to establish what is known about the antecedents of academic engagement and its consequences, while outlining outstanding research needs.

Our review confirms some previously established tenets regarding the antecedents of academic engagement; however, we suggest a number of new insights. First, based on the now larger body of research, we identify a greater number of factors that act as antecedents of academic engagement. For instance, we find that locally born and locally trained researchers, those with commercialisation and non-academic work experience, and those exposed to like-minded peers, are more likely to engage. Second, there has been a major step-change in terms of assessing the consequences of academic engagement in statistically robust ways; this research shows by and large that engagement has positive effects on research productivity and on other research-related performance measures.

Less progress has been made, however, on standardising engagement measures or survey questions and variables across countries. As before, it remains difficult to compare studies across countries and disciplines and draw general inferences. Taking stock in this manner of research on academic engagement in the 2010s also allows us to outline a research agenda for the next decade. Our review adds to the literature on academic engagement by providing researchers with a robust indication as to what factors play a role in academic engagement, and what outcomes are achieved, as attested across multiple studies. Simultaneously, we outline research opportunities by identifying those factors and outcomes where evidence is either conflicted or insufficient. On the basis of our synthetic insights, we also offer concrete suggestions on resolving measurement issues, highlight promising emerging areas of research and formulate policy conclusions.

\section{Background and motivation}

Academic engagement continues to be a subject of major policy interest, as science retains its promise to drive innovation across the economy and society. Since our last review, research funders have intensified their demands on science to make a "demonstrable contribution (...) to society and the economy". ${ }^{1}$ In the UK, previously separate research councils, bodies dedicated to funding public science, were integrated into a larger body named UK Research and Innovation with a broader remit that includes promoting innovation via science funding. Simultaneously, the UK government raised the incidence of the impact criterion in its evaluation of universities' research strength. ${ }^{2}$ The EU's Horizon Europe programme, starting in 2021, proposes the creation of a European Innovation Council as a "one-stop shop for high potential and breakthrough technologies". ${ }^{3}$ In the US, the National Institutes of Health (NIH) established the National Center for Advancing Translational Sciences (NCATS) in 2012, to facilitate faster development of treatments for disease. ${ }^{4}$

The increasing focus of science funders on innovation is important because academic engagement is regarded as a necessary vehicle to render science more impactful (Upton et al., 2014). UK Research and Innovation, for instance, states that "Encouraging even greater collaboration between business and the research base is key to achieving this ambition [of greater impact]". ${ }^{5}$ Many funding agencies, including those

\footnotetext{
${ }^{1}$ https://www.ukri.org/about-us/strategic-prospectus/delivering-economicimpact, accessed 06 July 2020.

2 https://re.ukri.org/research/research-excellence-framework-ref, accessed 06 July 2020.

3 https://ec.europa.eu/info/horizon-europe-next-research-and-innovationframework-programme_en, accessed 06 July 2020.

${ }^{4}$ https://ncats.nih.gov/about/center, accessed 06 July 2020.

5 https://www.ukri.org/about-us/strategic-prospectus/delivering-economicimpact, accessed 06 July 2020.
}

in the social sciences and humanities, ${ }^{6}$ encourage joint grant applications by universities and firms, and facilitate or subsidise firms' interactions with universities. Identifying the antecedents and evaluating the consequences of engagement, therefore, remain of central interest to those seeking to inform and design such policies.

Scholarly interest in academic engagement has kept pace with the perceived relevance of the topic. The volume of relevant work published since 2011 - the cut-off year for the previous review - is in fact larger than the number of articles covered previously over a much longer time period. A review of this body of work is warranted for three reasons. First, recent work on academic engagement remains fragmented. Extant work variously focuses on different types of engagement, e.g. collaboration, consulting or advising, and uses differing terminology to refer to specific types of engagement, making it difficult to compare research results across articles. Moreover, contributions tend to examine specific geographic locales or scientific disciplines. Second, since our last review, researchers have placed increased emphasis on specific determinants of academic engagement, such as gender and a scientist's geographic mobility, as well as on academics' underpinning motivations. Third, the new emphasis on the impact of science raises the question as to what aggregate evidence we have on the consequences of academic engagement, including possible repercussions for the evolution of science. Critical voices have warned that engagement, particularly with the private sector, may result in adverse consequences, such as increased secrecy or a neglect of fundamental scientific inquiry (Callaert et al., 2015; Czarnitzki, Grimpe and Toole, 2015; Münch, 2014; Slaughter and Leslie, 1997). Given the increased pressure for impact, there is a renewed need to establish to what extent these fears are empirically grounded.

Against this background, in this piece we intend to synthesise the extant body of research in a way that addresses the fragmentation of research, integrates recently added directions, and distils what is known about the impact of academic engagement. An updated review also provides an opportunity to test the robustness of the conclusions of the previous review and to assess progress in meeting the challenges we had identified.

\subsection{Conclusions from the previous review}

Our original review converged on three key insights. First, academic engagement is practiced primarily by scientifically productive individuals, suggesting it is complementary to, or even instrumental for, academic research activities. Second, relatedly, academic engagement is positively correlated with mobilising research funding and resources. Third, academic engagement appears, as compared to commercialisation activities, to be more driven by autonomous individual motivations and characteristics and less influenced by embedded university characteristics.

We also identified the major scholarly challenges for research in this area at the time. The first arose from the narrow coverage of countries in the literature reviewed, which focussed heavily on the US and the UK. This limited the possibility of comparing levels of activity across countries, or the impact of institutional differences on engagement patterns. We further noted that much of the available evidence on engagement - including the extent of activity, motivations, constraints, and effects - was based on self-reported surveys of academics. While yielding valuable insights, we noted a lack of standardisation of the definitions of academic engagement and scale formulation across studies, posing challenges to cross-study comparison. Furthermore, the cross-sectional nature of virtually all, other than case studies, data

\footnotetext{
${ }^{6}$ For instance, the UK Arts \& Humanities Research Council aims to address "the distinctive needs of the fastest-growing, creative sector of the UK's economy": https://ahrc.ukri.org/about/what-we-do, accessed 06 July 2020.
} 
posed obvious challenges to causal interpretation of many of the relationships discussed in the review. The samples analysed also varied in terms of disciplinary coverage and representativeness of underlying populations. The review urged the development of longitudinal surveys and archival datasets, an extension of country coverage and a standardisation of academic engagement measures.

We finally suggested a set of avenues for further research. These included exploring the role of organisational and institutional contexts for motivating academic engagement, the consequences and impact of the latter, and the relationship between engagement and commercialisation. This current update of our previous review provides an opportunity to take stock of the progress made in the current decade against the challenges, as well as the research agenda identified at the time.

\section{Methodology}

We approached this systematic review, substantially using the same procedures as in the previous article. First, we identified all relevant research published on academic engagement since April 2011, which was the cut-off point for the previous piece. We conducted a search of titles and abstracts of peer-reviewed articles referenced by the bibliographical database service EBSCO (including EconLit), with the search terms used for the previous review (Appendix A). Running these queries in May 2019 resulted in 3,628 publications. Next, we extracted all references to our previous review from Elsevier SCOPUS, which yielded an additional 529 publications. Responding to reviewer comments, we ran additional queries in February 2020 using a set of additional search terms (Appendix A), which yielded an additional 3,324 publications. Overall, we obtained 7,480 references.

We then checked for duplicates and applied inclusion criteria at the level of the journal. Specifically, we only selected articles published in journals listed in the 2018 Academic Journal Guide ${ }^{7}$ in the subfields of 'innovation', 'organisational studies', 'strategy', 'entrepreneurship and small business management', 'economics, econometrics and statistics', 'social sciences' and 'general management, ethics, gender, social responsibility', and appearing in the ranking with a score of 2 or more. We added the journal Regional Studies as it contains a large number of potentially relevant studies (24) after removing duplicates. After this procedure we were left with 1,392 unique articles.

We then filtered these articles based on fit. The most common reason for exclusion $(28 \%)$ was where a study did not focus on the individual level of analysis. These studies covered various aspects of university-industry collaboration, ranging from organisational structures for technology transfer and start-up creation to university strategies and aggregate analyses of engagement. The remaining reasons for lack of fit were, in descending order of occurrence: not focusing on academics (23\%), focusing on firms (16\%), providing theoretical models or reviews (9\%), focusing only on spin-offs or entrepreneurship (8\%), focusing only on patenting, licencing or commercialisation (7\%), treating other topics $(6 \%)$, or not meeting quality criteria (lack of clarity whether data had been collected in a systematic way or absence of unequivocal results) or duplicates (3\%). This procedure left us with a total of 58 articles, which we read and synthesised. We then compiled the following information for each article: research questions, data used, methodology, variables and results (See table in Appendix B).

Regarding the journals in which these articles are published, two journals (Research Policy and Journal of Technology Transfer) account for $60 \%$ of all articles (Table 1). Compared to the previous review, the topic attracted interest across a wider range of journals, and the country coverage of the research expanded significantly. The rate of publication amounts to around seven articles published per year; a significantly

\footnotetext{
${ }^{7}$ Available at:https://charteredabs.org/academic-journal-guide-2018, accessed 04/08/2020.
}

Table 1

Articles by journal, method and geographic focus.

\begin{tabular}{|c|c|c|}
\hline & $\begin{array}{l}\text { Previous review } \\
\text { (Number of articles) }\end{array}$ & $\begin{array}{l}\text { Current review } \\
\text { (Number of articles) }\end{array}$ \\
\hline Research Policy & 13 & 18 \\
\hline Journal of Technology Transfer & 10 & 16 \\
\hline Cambridge Journal of Economics & - & 2 \\
\hline $\begin{array}{l}\text { Economics of Innovation and } \\
\text { New Technology }\end{array}$ & - & 2 \\
\hline $\begin{array}{l}\text { Journal of Product Innovation } \\
\text { Management }\end{array}$ & - & 2 \\
\hline $\begin{array}{l}\text { International Journal of } \\
\text { Industrial Organization }\end{array}$ & - & 2 \\
\hline Organization Science & - & 2 \\
\hline Regional Studies & - & 2 \\
\hline Technovation & 3 & 1 \\
\hline The Journal of Higher Education & 2 & - \\
\hline Others & 8 & 11 \\
\hline Quantitative data & 33 & 51 \\
\hline Qualitative data & 3 & 4 \\
\hline Mixed & - & 3 \\
\hline UK & 18 & 16 \\
\hline US & 5 & 13 \\
\hline Other Europe & 11 & 22 \\
\hline Other countries & 1 & 7 \\
\hline Asia & 1 & - \\
\hline Sum & 36 & 58 \\
\hline
\end{tabular}

Breakdown of articles according to journal, type of data and geographic focus. *For the current review, 'Others' include Academy of Management Journal, Human Relations, Industry \& Innovation, Industrial \& Corporate Change, Innovation: Organization and Management, Management Decision, R\&D Management, Research Evaluation and Strategic Management Journal.

higher rate compared to the period covered by the previous review. As can be seen in Table 2, the most commonly investigated activities are: consulting (in 18 articles), contract research (13) and joint research (12). These counts should be interpreted as approximate because measures are not always unequivocally tracking specific activities. Where meaningful, we supplement findings from non-journal publications that present results from very large-scale data collection exercises (Davey et al., 2018; Hughes et al., 2016; Kongsted et al., 2017).

We present summary insights from all articles reporting regression results, variable by variable in the synthetic Table 3 . The variable definitions in this body of work are too heterogeneous to be subject to a quantitative meta-study. Instead, we used the following process to generate the entries in Table 3. We tabulated, article by article, all variables included in regression results. For each variable present in an article we entered either 'positive' or 'negative' if it was statistically significant, or 'non-significant' in the column for the respective article. If a given variable featured in two or more articles, we included it in Table 2. We subsumed variations in the operationalisation of a variable under the same variable. The value of the variable in the Table 3 was set to ' + ' if all values for the variable were either significant and positive or non-significant, and there were no significant negative values; it was set to '-' if all values of the variables were either significant and negative or non-significant, and there were no significant positive variables; and it was set to 'o' if values included both negative values and positive significant values, alongside non-significant values, if any.

\section{Results}

In this section, we synthesise the reviewed literature and report how the findings compare with key insights from the previous review. We first focus on the antecedents to academic engagement, grouped by level of analysis, and then move on to discuss the consequences of engagement for various types of outcomes. We conclude with a 
Table 2

Breakdown of types of academic engagement in reviewed work.

\begin{tabular}{ll}
\hline Activity & $\begin{array}{l}\text { Number of articles where activity is } \\
\text { measured }\end{array}$ \\
\hline Consulting & 18 \\
Contract research & 13 \\
Joint research & 13 \\
Informal contacts/advice & 8 \\
Training of personnel & 8 \\
Placement/supervision of students & 8 \\
Industry funding & 8 \\
Joint publications & 7 \\
Conferences/workshops & 7 \\
Membership in advisory boards & 5 \\
Joint creation of physical facilities & 3 \\
Work with standardisation bodies & 2
\end{tabular}

Table 3

Academic engagement: determinants and outcomes.

\begin{tabular}{|c|c|c|}
\hline Variable & $\begin{array}{l}\text { Current state of } \\
\text { knowledge }\end{array}$ & $\begin{array}{l}\text { Previous } \\
\text { review }\end{array}$ \\
\hline \multicolumn{3}{|l|}{ Individual determinants } \\
\hline \multicolumn{3}{|l|}{ Demographic attributes } \\
\hline Male & + & + \\
\hline Age & o & o \\
\hline Academic age & o & \\
\hline Tenure & o & \\
\hline Seniority (rank) & + & + \\
\hline Foreign born & - & \\
\hline Locally trained & + & \\
\hline Mobile & + & \\
\hline \multicolumn{3}{|l|}{ Prior career experience } \\
\hline Previous commercialisation experience & + & o \\
\hline Previous non-academic work experience & + & \\
\hline Previous entrepreneurship experience & o & \\
\hline \multicolumn{3}{|l|}{ Interdependencies with other activities } \\
\hline $\begin{array}{l}\text { Research productivity/Publication } \\
\text { count }\end{array}$ & + & + \\
\hline Research quality & o & \\
\hline Patenting & o & \\
\hline Publications in applied journals & + & \\
\hline \multicolumn{3}{|l|}{ Motivations } \\
\hline Expected benefit - Accessing resources & o & \\
\hline Expected benefit - Knowledge goals & o & \\
\hline Expected benefit - Personal income & o & \\
\hline Expected cost - Loss of freedom & - & \\
\hline \multicolumn{3}{|l|}{$\begin{array}{l}\text { Relational and organisational } \\
\text { determinants }\end{array}$} \\
\hline Peer effects & + & o \\
\hline Quality university/department & o & - \\
\hline Incentives for commercialisation & o & o \\
\hline \multicolumn{3}{|l|}{ Institutional determinants } \\
\hline Applied discipline & + & + \\
\hline \multicolumn{3}{|l|}{ Consequences } \\
\hline Research productivity * & + & o \\
\hline Secrecy/delay *** & + & \\
\hline Patenting & o & \\
\hline Start-up & o & \\
\hline
\end{tabular}

Notes: The table reports the determinants (vertical) of individual-level academic engagement, and the outcomes. A given variable was included in this table, only if it was featured in two or more articles.

Key: $(+)$ Positive effect in at least some studies. ( - ) Negative effect in at least some studies. (o) ambiguous effect/insufficient empirical evidence. Cells left blank for items not covered in previous review.

* While the effect on scientific productivity is generally positive, the effect is curvilinear in some studies, and is negative for highly applied types of engagement (e.g. consulting).

** The result for this item is informed by articles covered in both the current and previous review. summary in which we pay particular attention to the novel directions that the literature has taken since the previous review.

\subsection{Antecedents of academic engagement}

\subsubsection{Individual characteristics}

A first set of contributions addresses the impact of demographic attributes on engagement. Amongst these, gender has attracted particular attention, featuring in studies covering the UK, the US and Germany. In the UK, male academics are significantly more likely to engage with industry (Abreu and Grinevich, 2013, 2017; Tartari and Salter, 2015), and do so at greater breadth (Lawson et al., 2019). One study for the UK, covering all disciplines finds that, while not controlling for other characteristics, male academics' engagement in contract research and consulting work is almost double the amount performed by female academics (Abreu and Grinevich, 2017). However, female academics are more likely than males to use specific engagement modes, such as public engagement, meetings and informal advice (Lawson et al., 2016). Overall, the gender gap narrows considerably - without disappearing - once other individual differences are considered (Abreu and Grinevich, 2017). Interestingly, in the engineering and physical sciences, gender disparities reduce in disciplines with higher proportions of women. Pro-women policies at universities show strong effects, as the gender difference in engagement is present only in organisations with little formal commitment to supporting women's careers (Tartari and Salter, 2015).

There are three non-UK studies addressing the role of gender. The first, covering STEM disciplines in the US, shows no gender gap for patenting and furthermore reports that collaborating with industry increases the likelihood of patenting particularly for female academic scientists (Meng, 2016). The second finds no effect of gender amongst German material scientists on engagement in standardisation committees (Blind et al., 2018). The third shows that female academics in Denmark engage less with private organisations than their male counterparts, while no gender differences prevail with respect to public organisations(Kongsted et al., 2017).

Age (the biological age of an individual) continues to have an ambiguous effect. One UK study finds a positive relationship (Abreu and Grinevich, 2013), while another for a later period establishes a nonlinear effect with the youngest and oldest subgroups exhibiting a lower breadth of engagement than the middle age range (Lawson et al., 2019). One study for Italy finds no effect (Iorio et al., 2017), and another for the same country and similar disciplines finds only weakly significantly negative effects (Tartari and Breschi, 2012).

Academic age, usually operationalised as 'years since $\mathrm{PhD}$ ', and having tenure, also have an unclear effect on academic engagement, with one study finding a positive impact of both variables for the US (Schuelke-Leech, 2013), and others detecting no effect of tenure in Germany (Aschhoff and Grimpe, 2014) or of academic age in a German and Swedish sample (Huyghe and Knockaert, 2015). By contrast, seniority (how high an individual ranks in the academic hierarchy) is more robustly related with academic engagement, for example, in Italy and the UK (Abreu and Grinevich, 2013; Lawson et al., 2019; Tartari and Breschi, 2012). Boehm and Hogan's (2014) qualitative study illustrates how 'jack of all trades' principal investigators - generally senior academics - play a lead role in establishing and managing collaboration with industry. Ding and Choi (2011) find that, in the US, academics become advisors to a company later in their career, compared to founding a company, which typically occurs earlier.

Recent work has examined the effect of the international demographic characteristics of academics, which are increasingly internationally mobile and of diverse national origin (Scellato et al., 2015). Libaers (2014) shows that, in the US, foreign-born academic scientists have lower odds of being approached by a firm or serving as a consultant, compared to their US born counterparts. Tartari et al. (2012) complement this finding by proposing that UK scientists with a British 
$\mathrm{PhD}$ are culturally closer to their industrial partners and hence subject to lower "orientation" barriers in the domestic economy. This result is confirmed by Lawson et al. (2019) who find that having a British PhD is positively related to the breadth of domestic (but not international) knowledge exchange. They also find that foreign-born academics, compared to their home-born colleagues, engage less domestically but more internationally. The difference is small and weakens over time; both foreign born and domestic academics engage much more intrathan internationally. Edler et al. (2011) are not concerned with place of birth or locus of training but show that the most mobile scientists - in terms of visits to overseas research institutions - are more likely to engage with firms in both the visited and the home country. Similarly, Trippl (2013) analyses the effects of mobility on industry engagement in an international sample of the most highly cited Web of Science authors. She finds that geographically mobile scientists are as likely as their non-mobile counterparts to engage with firms operating in their new geographical location. Overall, these studies suggest that there is an advantage in domestic academic engagement to having a local $\mathrm{PhD}$ and being home-born; however, the relatively limited negative effect of being foreign-born weakens over time due to national acculturation effects.

A second set of articles investigates the links between academic engagement and prior career experience. Tartari et al. (2012) establish that among science and engineering academics in the UK, both prior experience with commercialisation and with work outside academia, are associated with lower perceived orientation barriers to collaboration. Lawson et al. (2016), for all UK academics, demonstrate that engagement is engendered by previous engagement, with repeat rates from $55 \%$ to $94 \%$ depending on the types of activity.

Previous entrepreneurship experience (founding a company) has a more ambiguous effect. Johnson et al. (2017) find that it has no effect on academic engagement - in their words "informal commercialisation" - intention amongst STEM academics in Scottish universities. Using a different measure for entrepreneurship, Barbieri et al. (2018) determine that in Italy co-publishing with their own firm reduces academics' copublications with other firms. This suggests founding a firm may compete with industry collaboration. Conversely, Abreu and Grinevich (2013), for a wider set of disciplines in the UK, find that both having owned a small company and having worked in the public or third sector are positively associated with subsequent engagement; previous experience in the public and not-for-profit sectors has the same effect in the UK and Norway (Gulbrandsen and Thune, 2017).

A third set of articles explores the interdependencies between academic engagement and other activities in an academic's portfolio, particularly research. Academics with more publications are more likely to engage (Aschhoff and Grimpe, 2014; D'Este et al., 2019; Ding and Choi, 2011; Tartari et al., 2014) but the effect of academics' research quality (usually measured by the quality of their publications) is more ambiguous (Ding and Choi, 2011; Tartari et al., 2014; Zi and Blind, 2015). As for further research and portfolio-related determinants, academics' tendency to publish in applied journals has a positive effect on their propensity to collaborate with industry in the Italian context (Tartari and Breschi, 2012). Similarly, German researchers who publish in applied and industry-oriented journals are more likely to engage in standardisation (Zi and Blind, 2015). The effect of patenting on collaboration is positive in an Italian context (Tartari and Breschi, 2012) and insignificant for the German life sciences (Aschhoff and Grimpe, 2014). Generally, evidence suggests significant correlation between different types of engagement, and between engagement and commercialisation (Schaeffer et al., 2020).

Further research for the US points out that engagement with industry is correlated with an academic's breadth of academic collaborations (Libaers, 2014), and in the UK with their interdisciplinarity (D'Este et al., 2019). Interdisciplinarity is more strongly associated with academic entrepreneurship and technology transfer, compared to research partnerships, and contracts and consulting (D'Este et al., 2019).
Finally, Thursby and Thursby (2011b) for the US find that faculty participation in licensing has a positive effect on research funding, both from the government and industry, with the impact being higher for industry funding.

Fourth, there has been increasing attention on the motivations underpinning academic engagement. Professional recognition ('ribbon'), as well as the attraction of intellectual pursuit ('puzzle'), emerged as key motivational factors for scientists' collaborative and commercial engagement in a large survey of UK scientists (Lam, 2011). Blind et al. (2018) report for Germany that involvement in technical standardisation initiatives or committees is motivated intrinsically ('puzzle') while patenting is motivated by 'gold' (e.g. income). The intention to obtain research funding is nevertheless still identified as a prime motivating factor for working with industry in Italy and Spain (Iorio et al., 2017; Ramos-Vielba et al., 2016; Tartari and Breschi, 2012). Emphasising a novel aspect, Iorio et al. (2017) find that pro-social objectives (engaging with third parties because it makes a difference for society) predict academic engagement in Italy. In contrast to prior work, the intent to learn (engaging with third parties because it allows one to acquire new knowledge relevant for research) is not found to be a significant predictor (Iorio et al., 2017). The latter finding contrasts with results from two large surveys in the UK and Denmark, indicating that one of the most frequently cited motivations was for academics to gain new insights in their area of research (Hughes et al., 2016; Kongsted et al., 2017). This result is supported by qualitative work by Ankrah et al. (2013). Inconsistent results across studies may partly reflect differences in empirical approaches, but overall, they suggest strong complementarity between engagement and research per se.

Additional insights into the drivers of academics' attitudes towards engagement are provided by Tartari et al. (2012) in their exploration of barriers to academic engagement in the UK. Interestingly, while previous work experience and experience as an academic entrepreneur are negatively related to orientation barriers, experienced academic entrepreneurs perceive higher levels of transaction-related barriers (Tartari et al., 2012). Further, the perception that engagement limits academic freedom and harms scientific credibility are found to be deterrents in Italian (Tartari and Breschi, 2012) and Spanish studies (Ramos-Vielba et al., 2016). In the UK, Hughes et al. (2016) show that transaction-oriented factors, such as lack of time and resources, university bureaucracy and lack of rewards are by far the most frequently cited barriers by academics.

Introducing the psychological construct of regulatory focus, Johnson et al. (2017) in their Scottish study suggest that an academic's intention to engage is positively impacted by their chronic promotion focus (an individual "plays to win"), and negatively affected by their chronic prevention focus (an individual seeks to avoid failure). This result may point to the nature of academic engagements as a supplementary activity in an academic's portfolio.

\subsubsection{Relational and organisational context}

Recent studies have paid particular attention to how academic engagement is informed by individuals' relationships with others in their social context, both intra-organisationally and beyond. A UK study shows that academics mimic their departmental peers when it comes to industry engagement, and the effects are stronger for junior faculty and weaker for star scientists (Tartari et al., 2014). This finding holds for Germany too: Aschhoff and Grimpe (2014) report departmental peer effects, in addition to personal peer effects (co-authors), in the sense that peers' orientation towards industry influences individual engagement. Similarly, Ding and Choi (2011) for the US find that network ties with other scientists who are entrepreneurs increases the chances of becoming an academic entrepreneur or a company advisor. For Germany, Slavtchev (2013) finds that engaging professors have a higher number of linkages with firms started by former assistants and students, and firms at the same location as the universities from which they 
received their $\mathrm{PhD}$. These results across several national contexts suggest that contextual and relationship effects are robust to cultural and institutional variations.

Compared to the relational context, organisation-level determinants have attracted less attention. A few studies consider the effect of the quality of the institution on engagement, using measures including a university's research intensity (Johnson et al., 2017) (no effect on commercialisation intention), research intensity rank (Libaers, 2014) (no effect on various types of engagement) or an index of departmental quality (Schuelke-Leech, 2013) (positive effect on various types of engagement). This research reveals no consistent pattern, primarily because of the variety of both quality measures and outcome measures used. In our last review paper, we reported an overall negative effect of organisation-level quality on engagement, yet this was based on a small number of studies which also differed substantially in their measures of both quality and outcomes (D'Este and Patel, 2007; Ponomariov, 2008). Overall, therefore, the relationship between organisation-level quality and academic engagement remains unclear.

A further set of contributions have examined various other aspects of the organisational context for academic engagement. A study by Halilem et al. (2017) found that incentives for commercialisation had an interesting side effect on academic engagement in Canada: the level of control exerted by a university (obligation to disclose) is inversely correlated with the level of academic engagement. Conversely, when royalty takes by the university are high, academics choose academic engagement, particularly consulting, rather than patenting and licensing, as a route to commercialisation (Halilem et al., 2017). Furthermore, one study finds that universities' entrepreneurial communication and culture in Sweden and Germany influences commercialisation (spin-off creation and IPR creation) but has little effect on academic engagement (Huyghe and Knockaert, 2015). Academics in UK institutions that give greater weight to commercial activities seem to be discouraged from academic engagement (Abreu and Grinevich, 2013). Both latter studies suggest that, at the very least, incentive structures for commercialisation are different from those for academic engagement.

Finally, as reported by Dolan et al. (2019), specially designed organisational contexts, such as cooperative research centres, can support academics in leveraging academic engagement for their research; for instance, by enabling multidisciplinary collaboration or the acquisition of resources.

\subsubsection{Institutional context}

Published work focuses on two pillars of institutional context: scientific disciplines and national regulations and public policies. Disciplinary affiliation is confirmed as an important variable shaping engagement with industry. Yet one interesting new finding is that engagement is not only practiced by academics from 'hard' technical disciplines (Hughes and Kitson, 2012). Along with colleagues from engineering, UK academics in business and media are the most prolific academic consultants (Abreu and Grinevich, 2013). Thursby and Thursby (2011a) find that US scientists in nanotechnology, biotechnology, and nanobiotechnology engage more strongly than those in other fields; their interpretation is that in these fields where new breakthroughs are achieved, one can observe a greater degree of tacit knowledge, requiring actual collaboration, rather than mediated knowledge transfer.

There is evidence on the effect of individuals' research orientation in the UK. One study partially supports the view that academics motivated to carry out basic research are less likely to work with industry (Abreu and Grinevich, 2013). The study by Lawson et al. (2019) confirm that those motivated by the pursuit of fundamental understanding (basic research) have a lower breadth of engagement activities than those motivated to carry out user-inspired basic research or applied research.

Most studies focus on North America and Europe, so little is known about other geographical contexts. A study of Mexican researchers categorises researchers into three types, namely whether they are engaged in basic science, applied science, and technology development, and finds that academics performing in either technology development or basic science interact with industry more than those conducting applied research (De Fuentes and Dutrénit, 2012). Arza and Carattoli (2017) emphasise the importance of personal networks in academic engagement at an Argentinian university, and Kruss and Visser (2017) find that individuals' reputation may form a barrier to engagement in South Africa. Variations in research design and sample coverage mean that cross country comparison is difficult and there are no studies attempting systematic cross-national comparisons.

\subsection{Consequences of academic engagement}

\subsubsection{Consequences for research}

The effect of engagement on research - the production of scientific knowledge - has been a long-standing question, and recent work has deployed some econometrically sophisticated methods. Of particular interest are implications for research productivity (number of publications per researcher) and research quality (quality of publications per researcher). Bikard et al. (2019) exploit evidence on simultaneous discoveries where several scientists (from a large cross country sample, of which $60 \%$ are US based) make roughly the same discovery around the same time. They find that academic scientists who collaborate with industry generate more follow-on publications. This finding, apart from confirming the existence of synergies between academic and industry research, suggests that science-industry collaboration enables a fruitful division of labour between academic scientists and their industry counterparts. ${ }^{8}$ According to Hottenrott and Lawson (2017), obtaining funding from industry is positively associated with both the number and the quality of subsequent publications for a sample of UK engineering academics, even though industry funding negatively moderates the impact of public/non-profit grants on these measures. Similarly, Garcia et al. (2020) in a study of Brazil also determine that particularly long-term collaboration has positive effects - at a decreasing rate - on the number of publications of academic research groups. However, based on evidence on a large sample of UK engineering academics, Banal-Estañol et al. (2015) find that obtaining research funding from industrial partners positively affects the number of publications, yet only up to a point from where research productivity declines.

There is increasing evidence that the effect of engagement with industry is contingent upon the type of collaboration. Rentocchini et al. (2014) establish for Spain that engaging in consulting is negatively correlated with research publications in the subsequent period in the natural sciences and engineering, with no effect in the medical sciences, social sciences and humanities. Another contingency is academics' strategic intent when engaging with industry. Callaert et al. (2015) reveal, using a Belgian and Italian sample, that when academics initiate projects (as opposed to reacting to requests), and are selective (e.g. refuse some requests), their collaborations result in higher scientific output.

A further set of contributions investigates the effects of engagement with industry on academics' fundraising. Fini et al. (2018) find that, for the majority of academic scientists at a large UK research university, raising funding for contract research from industry positively affects academics' ability to obtain public grants, suggesting that success with industry increases their standing amongst academic peers who review and evaluate their grant proposals. This is consistent with the findings of Hughes et al. (2016), in that $60 \%$ of UK academics report

\footnotetext{
${ }^{8}$ According to Mindutra (2013), complementarities between firm and industry with respect to scientific publishing represent one of the drivers that match certain academics to certain firms.
} 
engagement as having strengthened their reputation in their field. However, Fini et al. (2018) report that the effect they identify is curvilinear, as the ability to obtain grants turns declines for academics with very high levels of industry contract research funding. Relatedly, Melkers and Xiao (2012) find for the US that co-patenting with industry is positive for public grants, while the effect of collaborating with industry on product development is insignificant.

More broadly, researchers have continued to examine the effects of industry engagement on the conduct of public science. In two related studies, Czarnitzki and colleagues find for Germany that while obtaining external funding in general does not affect scientists' preparedness to openly share data or materials, scientists with industry funding are twice as likely to deny requests by other scientists for research input, delay publication and practice secrecy (Czarnitzki, Grimpe and Pellens, 2015; Czarnitzki, Grimpe and Toole, 2015). With regard to collaborative behaviour, Clark (2011) shows that US academic scientists working with industry collaborate more, across all engagement types, than those who do not. However, they also find that industry collaboration appears to crowd out intra-academic collaborations.

There may also be consequences of engagement for scientists' careers. Lam and de Campos (2015) report that early career researchers involved in collaborative research often experience tensions with respect to pursuing their academic careers. They agreed to help their senior supervisors with their engagement projects in return for help with advancing their own careers.

Finally, there is some research on the effect of engagement on teaching. Bianchini et al. (2016) conclude, for Italy, that the consulting opportunity effect on teaching quality is negative since they observe a lower commitment to teaching in profession-oriented disciplines such as civil engineering, whose members tend to perform extra-academic engagements. This is in contrast to self-reported positive effects of academic engagement on teaching across all disciplines in the UK where over $50 \%$ report benefits in terms of improved presentation of material and around 40\% report improved course structure and teaching reputation, and over $30 \%$ increased the employability of students (Hughes et al., 2016).

\subsubsection{Commercial consequences}

Academic engagement, apart from affecting scientists' scientific outputs, also has commercially relevant effects. For example, in Israeli nanotechnology, collaboration with industry - at least up to a certain optimal point - facilitates knowledge application, resulting in outputs such as preliminary studies, prototypes, testing and commercialisation (Lavie and Drori, 2012). There are multiple studies suggesting that engagement with industry increases academics' inventive prowess as measured by patents, filed or obtained. Lawson (2013) determines that UK researchers with a large share of industry funding their portfolio file more patents. More specifically, Goel and Göktepe-Hultén (2013) studying scientists at the Max Planck Society in Germany determine that both collaboration and consulting have positive effects on patenting, with the magnitude for industrial collaboration being greater. Interestingly, the more scientists work with industry, the more they bypass their technology transfer office when patenting (Goel and Göktepe-Hultén, 2018), meaning these patents are assigned to an external entity and not their university - a phenomenon highlighted by a recent study of a UK research university (Perkmann et al., 2015). Finally, having been contracted by a firm in the past positively influences patenting volume and quality for Quebecois academics (Beaudry and Kananian, 2013) and spending time collaborating with industry positively influences the propensity of US academics to patent and commercialise within those collaborations (Libaers, 2017), although yet again in both cases the relationship shows an inverse U-shape. However, Bikard et al. (2019) provide a dissenting result using international data, suggesting that academics who work with industry patent less than comparable colleagues not working with industry; they suggest that this may be due to the fact that mixed academia-industry teams establish a division of labour where academics focus on publishing while industry partners focus on patenting.

There is also a set of contributions addressing how academic engagement affects academics' entrepreneurial activities. German academics with prior experience in $R \& D$ cooperation with private sector firms are more likely to report that the idea of starting a business is attractive (Fritsch and Krabel, 2012). However, for the US, Ding and Choi (2011) find in the specific case of being a company's scientific advisor, that the probability of becoming an academic entrepreneur declines.

\subsection{Summary of results}

Recent work confirms and substantiates key insights drawn in the original survey, namely that: 1) academic engagement is complementary to, and in line with, furthering academic research activities; 2) scientifically productive individuals are more likely to engage than other academics; 3) academic engagement is positively correlated with mobilising research funding and resources; and, 4) academic engagement is driven by individual motivation and characteristics, rather than university characteristics.

Moreover, the notion of academic engagement has remained rather stable and consistent with influential earlier contributions (Bonaccorsi and Piccaluga, 1994; Meyer-Krahmer and Schmoch, 1998; Schartinger et al., 2002). However, the current review demonstrates that research about academic engagement has taken a number of new directions, which go beyond the fact that, empirically, researchers have added to the studied range of activities that can be subsumed under academic engagement. They have done this, notably, by examining engagement in standardisation committees and participation on advisory boards.

As can be seen from the comparison between the previous and current review in Table 3, recent research has explored a variety of new factors, both as determinants and outcomes. Recent studies also provide more evidence on previously foregrounded factors. As a result, we have a much more complete picture of academic engagement than before. We now comment on the most notable results and outline the progress made since the previous review.

Amongst individual-level antecedents for academic engagement, recent work has explored the gendered nature of academic engagement with industry; in the UK the evidence is the clearest; in general women engage less, even after controlling for other individual-level attributes, and recognising engagement channels that seem less gendered that others. Researchers have shown a growing interest in how individuals' social environment or their networks affect engagement: academics mimic academic engagement behaviour, of both their local and nonlocal peers, as well as of individuals within their networks.

Researchers have also paid growing attention to the role of individuals' nationality and international mobility for academic engagement. Evidence from published work suggests strong national anchoring and acculturation effects in the domestic economy. International mobility results vary, but often show that mobility enhances engagement both at home and abroad, rather than crowding out domestic activity.

Recent work provides new evidence on the interdependencies between different activities in an academic's portfolio. While ambiguous in the previous review, there is now evidence of a positive spill-over of commercialisation (activities pertaining to intellectual property and academic entrepreneurship) into subsequent academic engagement with industry, with one exception: start-up activity may compete with it, at least temporarily.

Some of the reviewed studies considered antecedents to both academic engagement and commercialisation, offering an opportunity for comparison. Regarding gender, Abreu and Grinevich (2013) highlight a gender gap applying to both engagement and commercialisation. Peer 


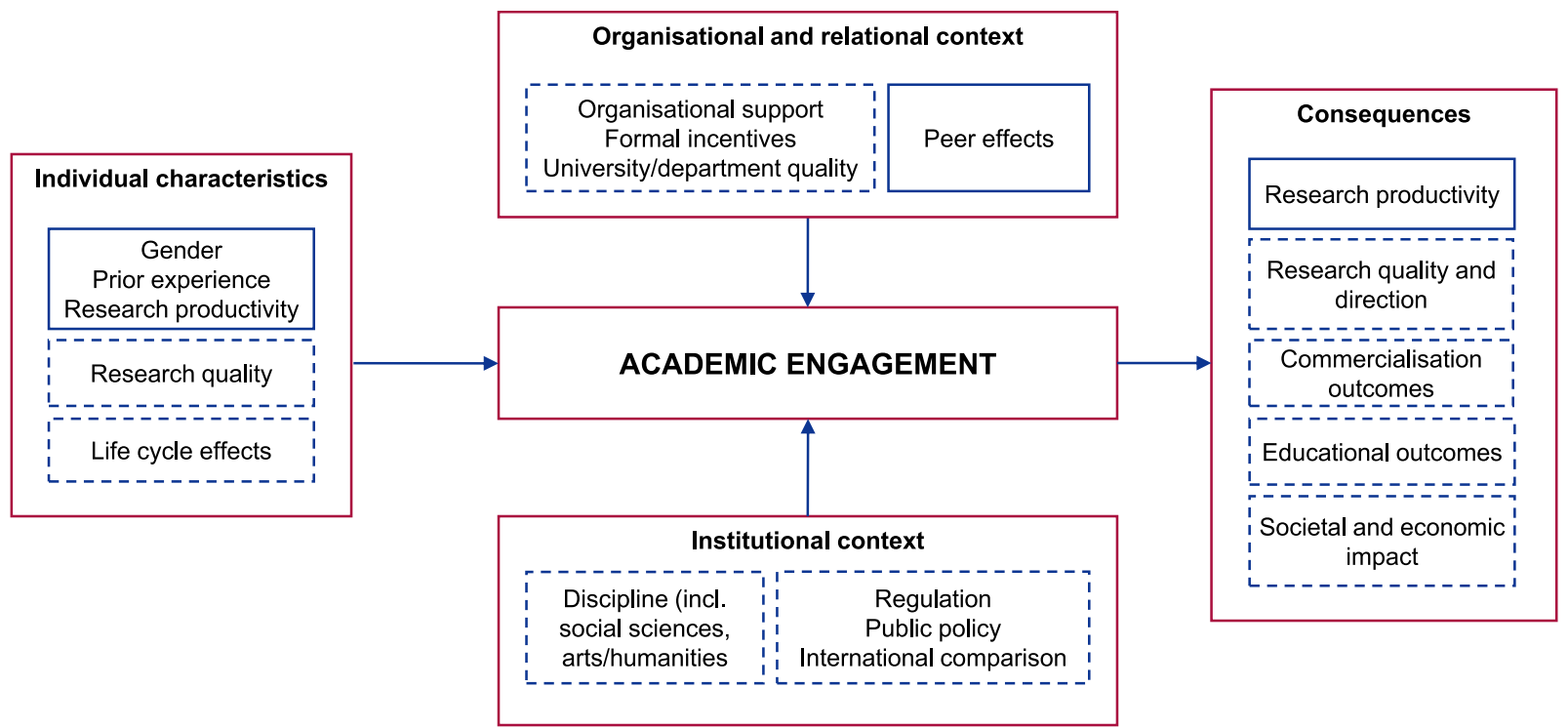

Fig. 1. An analytical framework of academic engagement.

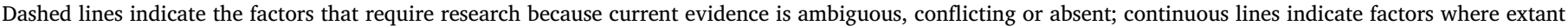
research is relatively convergent.

effects, including the influence of colleagues (Johnson et al., 2017), coauthors (Aschhoff and Grimpe, 2014), and the presence of role models (Huyghe and Knockaert, 2015), also appear to affect commercialisation in a similar way to academic engagement. The effects on academic engagement of mobility also extend to commercialisation (Edler et al., 2011; Trippl, 2013). While the number of studies remains small and differences in the magnitudes of these effects persist, these results suggest - on an individual level - significant complementarities between engagement and commercialisation.

One interesting insight that has come to light is that, with respect to antecedents of engagement, research productivity does not equal research quality. Academics with more publications are more likely to engage, but the relationship between scholars' research quality and engagement is unclear. Moreover, in the previous review we noted an inverse relationship between university or departmental quality and engagement, but now, with more studies added to the picture, the relationship has become ambiguous (see Table 3).

With respect to the consequences of academic engagement, recent work has made significant progress on substantiating the effects on academic productivity, with a number of contributions, finding a largely positive relationship and some evidence of a curvilinear relationship. A newly addressed aspect has been the effect of engagement on an academic's ability to obtain grants, which can be seen as a leading indicator of subsequent scientific productivity. Results again point to a positive relationship, with some evidence for curvilinearity affecting a minority of 'extreme' collaborators. Interest in the effects on research direction and secrecy has waned, with a decreasing number of contributions that however confirm previous research. Conversely, more attention has been paid to the commercial consequences of engagement, whereby at this point there is no clear consensus with respect to its effects on the creation of intellectual property (measured primarily as patenting) or the founding of academic start-ups.

Conceptually speaking, most research on academic engagement has remained phenomenon-driven and theoretically eclectic. However, the literature offers a theoretically richer picture compared to the previous review. We are able to distinguish three main theoretical directions, of which the first two relate to antecedents and the third relates to the consequences of engagement. First, a number of works draw on the sociology of social influence to explain researchers' decision to engage. In this view, the researcher is conceptualised as part of a community or group that influence their individual engagement behaviour
(Aschhoff and Grimpe, 2014; Haas and Park, 2010; SchuelkeLeech, 2013; Tartari and Salter, 2015). Related are contributions that theorise engagement from an identity perspective: engagement represents an identity marker that will be judged variably by different audiences (Fini et al., 2018). A second set of articles view academic engagement from an organisational behaviour perspective. Here, the propensity to engage is explained either on the basis of - more rarely an individuals' personality characteristics (Johnson et al., 2017) or more commonly - belief systems, which in turn inform their motivation to engage (Ding and Choi, 2011; Lam, 2011). In the latter view, academics are intrinsically motivated to participate in engagement when they perceive the activity to be aligned with their internalised value system of public science or may be extrinsically motivated to do so if offered certain rewards (Lam 2011). A third set of contributions use insights from innovation theories, specifically around knowledge combination, networks and tacit knowledge, to explain outcomes from academic engagement (Beaudry and Kananian, 2013; Lavie and Drori, 2012; Melkers and Xiao, 2012; Thursby and Thursby, 2011a). In this view, the researcher is situated within an interpersonal network, and outcomes are determined by their position within this network. Overall, compared to the previous period that was predominantly characterised by phenomenon-driven approaches, recent research has shown progress in terms of framing academic engagement in existing bodies of theory, and deriving predictions and explanations therein.

\section{Discussion}

\subsection{Agenda for future research}

We present the results from our review in Fig. 1, which highlight areas where extant research provides relatively robust evidence (continuous lines) versus those requiring future research (dashed lines). The figure synthesises the information contained in Table 3 which is based on the cumulative knowledge gain from both this review and the previous review. Below, we discuss promising questions arising from this analysis in detail. Answering these questions will contribute to creating a more comprehensive picture of the antecedents and consequences of academic engagement.

First, further investigation is required on the individual-level antecedents of academic engagement (left-hand side in Fig. 1). The finding that research productivity, but not necessarily research quality, drives 
engagement calls for more research on the boundary conditions under which the 'best' academics engage. These conditions may include the types of engagement or life cycle effects, i.e. at which point in their career academics engage. Life cycle effects require exploration in their own right, as the role of both biological and academic age remains unclear in the present research. While traditionally, engagement was viewed as driven by experienced academics' intent to exploit their expertise accumulated earlier in their career (Levin and Stephan, 1991), younger faculty may be inclined to engage if engagement is conceived as complementary with research. Moreover, given that we know little about the dynamics of engagement processes, research could explore the process by which academic engagement is entered into, exited from, or persists. Work on early stage career academic engagement activity in particular would seem potentially fruitful here since pressures to publish, rather than enter into academic engagement, are highest at this stage.

Second, we require additional research on the organisational and relational context from which academic engagement is conducted (top box in Fig. 1). A basic question here is how the quality of the university or department - in terms of members' aggregate research prominence affects the volume and type of engagement undertaken by individuals. Faculty in highly ranked departments may have fewer incentives to engage, as they focus on research and control sufficient resources (D'Este and Patel, 2007); simultaneously, they may have more opportunities to engage, as external stakeholders are attracted to these departments (Mansfield, 1995).

Further, we still know relatively little about the role that departmental or university-level support plays in facilitating faculty participation in academic engagement. While traditional technology transfer support appears to be less relevant, we have yet to learn about whether and how alternative structures put in place by universities, such as industry liaison offices or dedicated policies, effectively encourage engagement. Equally, research on whether certain incentive structures work to modify and influence academics' engagement patterns is largely absent, and could be complementary to prior work conducted for commercialisation activities, such as licencing (Jensen and Thursby, 2001).

Third, we encourage future work on the role of the institutional context as antecedent to academic engagement (bottom box in Fig. 1). Research should contrast the behaviour in terms of research orientation, engagement and impact of academics carrying out publicly funded research in intermediate or hybrid research organisations, compared to those in university departments per se (Van Looy et al., 2006). Some countries (e.g. Germany) have multiple publicly funded research institutions with differing emphases while others (e.g. UK) have a more homogeneous institutional structure with publicly funded research dominated by the university sector. However, in many of the latter contexts (e.g. UK or US), we have witnessed a proliferation of hybrid university-industry research centres (Bozeman and Boardman, 2003; Perkmann et al., 2019). Engagement in these structures tends to be higher, whereby extant research offers tentative evidence for positive effects of these centres on research (Coberly and Gray, 2010; Gaughan and Corley, 2010; Lin and Bozeman, 2006; Van Looy et al., 2006). Research should address the consequences for research productivity and research quality in the long term across different types of hybrid structures and institutional set-ups.

Still with respect to institutional context, a further opportunity for institutional comparison is represented by the ever more pronounced role of middle-income and developing economies in global science and related repercussions for academic engagement in these contexts. Most extant research is narrowly focused on a small number of countries, and it is therefore important to evaluate potentially differing antecedents and consequences of academic engagement (e.g. Kafouros et al., 2015). Moreover, while most work has been focused on the hard sciences of engineering and medicine, we need to know more about what academic engagement means for other disciplines, such as the social sciences and arts and humanities, and whether findings from the traditionally covered disciplines can be generalised. For instance, social scientists have a lower need for external funding, but governments often commission them to generate policy-relevant studies. These factors could influence both inputs and outputs of academic engagement differently in the social sciences and humanities, compared to the hard sciences.

Fourth, more research is required on the consequences of academic engagement (right hand-side box in Fig. 1). While by now we have evidence for a positive effect on the subsequent research productivity of academics, we have only tentative evidence on the effect of engagement on the quality of their publications, including whether the potential for breakthroughs increases. We also need to learn more about the effects on the direction of research, beyond the question of whether engagement pushes academics towards more applied research, for which there is little evidence (e.g. Van Looy et al., 2006). Notably, it would be interesting to know whether academic engagement propels scientists to be more exploratory in their research - moving into new areas and tackling new problems - which may potentially lead to more variance in research impact. From a policy viewpoint, establishing the effects on both quality and direction of subsequent research is important as there may be trade-offs between encouraging engagement and safeguarding the quality and inventiveness of the science system (Huang and Murray, 2009).

Also, work in this area should address the overall portfolio of activities by academics, and specifically examine the interdependencies of engagement with other key academic activities, especially teaching, through which the impact of engagement may be transmitted. Methodologically, all of this may include developing more longitudinal case studies, based on qualitative or narrative approaches. These are already increasingly used in the evaluation of uncertain long term innovation policies (Hughes and Martin, 2012). Such a case study approach is also embedded, for example, in the assessment of impact used in the UK Research Excellence Framework (REF) for evaluating the research performance of universities (Khazragui and Hudson, 2015).

\subsection{Emerging topics}

In discussing future research, there is also a need to reflect on how and why academic engagement relates to broader emerging themes relating to the evolution of public science and its relationship with industrial $\mathrm{R} \& \mathrm{D}$. In this section, we suggest some promising areas and outline how future research on academic engagement may effectively contribute.

The theme of the socially engaged university has recently gained prominence (Grau et al., 2017). Rather than being narrowly focused on a commercially-induced impact, universities are called on to seek impact via additional channels, such as civic engagement (Fecher and Friesike, 2014) and instructional designs for researchers and students to co-deliver social innovations (McKelvey and Zaring, 2018). The concept of socially engaged university chimes with the values held by many academics individually (Lee, 1998). Historically, certain types of universities, such as the land grant universities in the US, the technical universities and the grandesécolesin Europe were instituted with the explicit intent of supporting industrial and social evolution (McDowell, 2001; Rüegg, 2004).

Even though we explicitly expanded our search scope to include recent work on academic engagement relating to this topic, few studies have sought to address it. Exceptions include work on social motivations towards academic engagement (Iorio et al., 2017) and socially oriented channels for engagement (Hughes and Kitson, 2012). There is an opportunity, therefore, for future work to pay more attention to the social impact of academic engagement. This may include categorising the various ways in which social impact may be achieved via the conduct of public science, the implications for the design of incentives - or indeed the need to provide incentives - by universities, and considering how technology transfer offices or similar units need to be structured in 
order to enable social engagement.

Another promising area for future research - interrelated with social engagement - is the theme of open science and its relationship with academic engagement. Recent developments within science have included trends towards open publishing (Tennant et al., 2016), open data (Nosek et al., 2015; Perkmann and Schildt, 2015) and open source (Tennent et al., 2020), but the research on academic engagement has only considered the relatively narrow question of how working with industry affects scientists' disclosure behaviours. One important question is: to what degree and in what way will a shift towards more open norms and practices affect academics' relationships with actors that would conceivably resist openness, e.g. industry and other knowledge users? Another, equally pertinent question is: to what degree are changes in industry propelled by pressures for openness (Friesike et al., 2015; Jong and Slavova, 2014), for instance in clinical trials (Ross and Krumholz, 2013), which affect industry's relationships with academics who often pursue their own commercial interests and may be reluctant to accept the extension of open science norms to benefit private interests? Finally, the trend towards openness also appears to open up academic engagement to new audiences, such as crowds and citizens (Franzoni and Sauermann, 2014). It would be interesting for research to provide evidence on the antecedents for scientists to attract new audiences to their quests, the impact of these efforts on science itself, as well as its impact on these audiences.

\subsection{Analytical challenges and measurement}

The research published since 2011 has made notable progress on tackling some of the analytical challenges we emphasised in our previous review. In this section, we assess the progress made and identify areas where further work is required.

\subsubsection{Methodological advances in recent research}

Researchers have made substantial advances in terms of addressing identification problems and establishing causation, rather than correlation, by using a variety of methods; for instance, some authors use matching techniques to mitigate selection bias. Using naturally occurring matched pairs, Bikard et al. (2019) exploit the occurrence of simultaneous discoveries (where multiple scientists make approximately the same discovery around the same time) to address the challenge that research projects that involve industry collaborators may be qualitatively different from those that do not. Fini et al. (2018) use coarsened exact matching to create pairs of scientists that are similar in important dimensions, yet differ with respect to the treatment of interest (having obtained industry contracts). To estimate the effect of collaboration on the scientific production of research groups, Garcia et al. (2020) use a difference-in-differences approach with propensity score matching. To explore the existence of substitution effects between different forms of technology transfer, Barbieri et al. (2018) match academic entrepreneurs with similar non-enterprising colleagues, to prevent an overestimation of the impact of entrepreneurship on scientific productivity. Lawson et al. (2019) for their analysis of the impact of nationality on engagement, use semi-parametrically matched samples of foreign and domestic born academics. Tartari and Salter (2015) use a non-parametric matching procedure to consider gender stratification in science when estimating women researchers' propensity to engage in collaboration with industry. In a different approach, Mindruta (2013) introduces a theoretical matching model that explicitly deals with the endogeneity problem created by self-selection.

Other authors take yet different approaches to tackling the problem of endogeneity. Banal-Estañol et al. (2015) use an instrumental variable approach by specifying a variable that is correlated with academic engagement, but not with the production of scientific output. Halilem et al. (2017) use multilevel models for a population of 2,230 professors in 27 Canadian universities to test the effect of three features of institutional intellectual property right policy on the formal and informal commercial behaviours of faculty members. Lawson et al. (2016) use two waves of their survey of all UK academics to measure entry into and exit from academic engagement as well as its persistence in a panel of academics responding to both surveys. Overall, by using these various techniques and new data, recent work has made substantial progress in terms of tackling identification problems and hence ensuring greater validity of results.

\subsubsection{Outstanding measurement issues}

Less progress has been made, however, in relation to the standardisation of engagement measures or survey questions. The lack of standardisation is in contrast to the state of affairs in innovation studies where standardised measures have enabled extensive analytical comparisons between countries and over time (OECD, 2005). An exception is the study by Davey et al. (2018), which presents data on academic engagement based on a single survey instrument administered in 28 European countries; the study does not however conduct any systematic cross country analysis.

The case for standardisation rests on two arguments. First, the use of standardised measures would facilitate the replication of results across contexts and help build a more robust picture of academic engagement. Notably, researchers would be able to conduct meta-analyses, which is currently impossible due to the inconsistency of measures. Second, standardisation would provide those interested in policy with more reliable evidence on the incidence of academic engagement across contexts. For instance, having comparable figures would help policy makers understand how their context compares to others and which areas or aspects require policy intervention.

One way to address these issues is of course to rely, to a stronger degree, on archival data, rather than survey data. Research conducted during the last decade has indeed made stronger use of information on, for instance, co-authorship and co-inventorship with industrial partners or research contracts, to measure academics' engagement. The advantage of using this type of information is that it allows for relative precision and comparison across contexts. However, the measures based on archival information tend to disregard interactions that are not captured by administrative records, and are usually focused on specific types of activity. Tijssen et al. (2016), discussing metrics based on university-industry co-authorships, indeed warn that any specific measure cannot provide a holistic representation of a phenomenon.

To obtain a more comprehensive picture, archival data can be meaningfully complemented by surveys using standardised measures. One barrier to standardisation is the large variety of activities that come under academic engagement. The problem is exacerbated by the use of various terms referring to similar, partially overlapping activities, such as joint research, collaborative research or sponsored research. What defines specific types, such as consulting or joint research, differs from context to context. Further issues pertain to the time intervals and the types of external collaborators. Extant work uses varying time windows for tracking activity, ranging from one-year windows to the whole career of academics. It also refers to different types of external collaborators, ranging from private companies to government and even the broader public. While this expansion is positive in terms of further capturing the phenomenon, these external collaborators may also condition somewhat different categories of academic engagement, involving different motivations and consequences.

To address these issues, we suggest future work on creating and validating a set of scales for measuring academic engagement. Previous efforts have proposed a single index for capturing all activities subsumed under academic engagement, but this still relies on the separate characterisation of different activities, such as consulting, that are then weighted and aggregated (Bozeman and Gaughan, 2007; Tartari et al., 2014); a related study is conducted by Schuelke-Leech (2013).

We propose that this work should go further by developing more precise measures for capturing activities, such as consulting or sponsored research, independently from their institutional context, and by 
using suitable count units, such as the number of consulting days or the number of projects. We also suggest that separate account should be taken of different activities - thus avoiding lumping them into arbitrary groups - and then creating synthetic indices so that other scholars can unpack the measures if necessary. The time interval for which the information is requested should allow for the relative rarity of these activities for most academics, suggesting an interval of three years is appropriate. To assess the type of audiences to which academics engage, a comprehensive inventory of partner types could be created where respondents are asked to indicate the extent of attention they dedicate to each.

Innovation with respect to the instruments used for capturing academic engagement should suitably build on theoretical advances made in recent work, as summarised earlier, as well as on additional bodies of theoretical work. For instance, work on organisational and professional identity could inform instruments that capture the influence of an academic's identification with the university or academic community on their decision to engage (Foreman and Whetten, 2002). Work in institutional theory may underpin an attempt to capture variations in the degree to which individuals perceive their organisational or disciplinary context as relatively pure (dominated by public science principles) or hybrid (exposed to both public science and commercial principles) (de Wit-de Vries et al., 2019; Pache and Santos, 2013). Social psychology may inform the design of scales depicting a scientist's value orientations and motivations, as successfully illustrated in Lam's (2011) work. However, questionnaire scales should only be used when the requested information can reasonably be assumed to be held by individuals. For instance, outcomes from academic engagements tend to be more reliably tracked by archival data as individuals may not be aware of these outcomes or find it onerous to look them up.

More broadly, considering the emerging themes outlined above, e.g. social engagement and open science, requires us to gain more insight into the effects of engagement on the generation of actual impact, social or otherwise. This should be linked to a discussion of more refined measures of impact. Measures such as patents or even licences indicate commercial potential, yet they do not measure impact as such, let alone social impact. There is a need to develop measures for actual impact, which could cover, not just the development of new products, but also less tangible outputs such as the creation and diffusion of new medical practices or treatments, new policies or services. Furthermore, we know little about the process by which engagement with academics will generate outputs within partner organisations that in turn lead to impactful outcomes, both commercially and socially. There is an opportunity, therefore, for future research to: (a) devise new measures of how to track less tangible outcomes from engagement; and, (b) to examine the partner-side processes and effects of academic engagement, rather than taking a solely intra-science perspective as much research has to date.

\section{Conclusions and policy lessons}

In this article, we provide an updated review of the state of the art in the literature on academic engagement. We note that much progress in understanding this phenomenon has been made in the recent period, particularly with respect to establishing key antecedents to academic engagement, as well as robustly documenting its consequences for research, and, to a degree, for commercialisation outcomes. We identify areas that require further research, including the link between engagement and impact outcomes, between engagement and research outcomes, and the organisational and institutional mechanisms through which engagement results have an impact.

In our original review we drew policy lessons, which are interesting to return to in light of this review. We argued that a focus by policy makers and universities on technology transfer, privileges commercialisation over academic engagement, which is more frequent and generates a considerable, yet not as easily measurable, impact. Academic engagement arguably requires different support structures at policy, university and departmental levels. Moreover, engagement and societal impact require external parties to have the motivation and ability to manage academic relationships, hence solely focussing on academia policy is insufficient. Finally, we argued that policy must embrace the diversity of different types of academic institution, rather than wholly basing policy design on a model of research guided by Mertonian norms, values and conventions.

The insights from the current review reaffirm these lessons but also suggest new policy implications. The new results on gender and internationalisation suggest more attention should be paid to evaluating the needs and demands of different constituencies within academia and, if so desired, ameliorating specific barriers to engagement. In both cases it is helpful to consider implications for both government and university policy.

The findings on gender indicate that women follow different engagement paths and are somewhat less likely to engage in general. The gender effect diminishes once other characteristics such as age and seniority are allowed for, and when university policies to support gender equality are considered. From a university policy perspective, in ensuring equal access to engagement, specific support should, therefore, be embedded in a wider commitment to support the development and promotion of female academics. The role of government policy here could include tying an institution's eligibility for research grants to meeting agreed gender specific practices. An example is the UK is the Athena Swan award scheme. Universities voluntarily apply for awards (gold, silver and bronze) which are given or declined following an assessment by an independent non-governmental body. This scheme has been widely adopted in the UK and its effect reinforced in the medical sciences by the decision of the National Institute of Health Research to restrict eligibility for funding to institutions holding at least a silver award (Ovseiko et al., 2019).

In the case of international mobility, a similar two-level policy approach may be required, with the aim of supporting foreign-born scientists - who are initially relatively isolated - in their individual efforts to create connections with external organisations in the destination economy. Government policy could support individual acculturation by funding secondments and other interaction opportunities with domestic organisations, and universities may create specific networking schemes for newly arrived PhD students or faculty.

For university policy, an important research finding in the current review is that behaviour is conditioned by the relational context in which individual academics operate. Academics follow the lead of their departmental peers, and others in their proximate networks (both within their institution and outside), when deciding to engage. This has particular implications, both at university and departmental level, in terms of the criteria used in recruitment and promotion. Here, publications and research per se dominate whereby engagement plays a small part. Universities and departments intending to encourage engagement may provide enhanced visibility to those who already engage, particularly if they are scientifically productive. Caution should be exerted with respect to junior colleagues' engagement as the latter may compete with the requirement to publish and attain tenure. The available evidence on social contexts suggests university and departmental measures should be designed to expose individuals to the benefits of engagement but minimise the pressure to commit research time and resources (e.g. through master classes or involvement in projects with engagement undertaken by more senior team members). Both of these lines of policy should enhance informed choice about engagement activity.

In the context of government policy, for senior academics, an approach based on social influence and setting examples could be complemented by facilitating the formation of hybrid organisational structures. These structures, such as university-industry centres, enable industry to collaborate with established university research leaders in ways that maximise the distinctive capabilities that academia brings 
(Perkmann et al., 2019). The use of central government research funding favours the creation of such intermediary organisations, which can play a central role in increasing the diversity of publicly funded research-based institutions. Examples include the UK Catapult Centres (Hauser, 2014) and the Australian Co-operative Research Centres (AllenConsultingGroup, 2012), among others. These encourage universities to adopt strategic organisational and collaborative engagement practices and hence opportunities for self-selection by academics into such environments. The engagement aspect can be further reinforced by the requirement of matched 'user' funding from the business sector to trigger public funds. Based on existing evidence - which does not provide unequivocal support for a positive effect of research engagement on research quality - university management must decide on a case by case basis as to whether bidding for such funds should be encouraged from both a resource and a research quality point of view and seen as part of a portfolio of activities across organisational contexts.

A further implication for university policy is that, while the individual-level drivers for both engagement and commercialisation largely overlap - suggesting complementarities between the two - organisation-level drivers differ. The implication for university management is to design support structures at university or department-level, suitable for both building 'pipelines' of potential external partners as well as facilitating collaboration in a way that serves the purposes of both faculty and external organisations. This will mean expanding an exclusive focus on the management of intellectual property towards an approach that recognises broader complementarities between academic and industrial research, including mutual learning opportunities and integration with teaching. Intellectual property management capability should however be preserved, because academic engagement often results in intellectual property and is pursued interdependently with commercialisation.

Overall, our policy conclusions reaffirm the lessons drawn in our previous review but also propose stronger emphases - at both government and university policy levels - with respect to the diversity of academia in terms of gender, nationality and seniority, as well as organisation-level mechanisms through which engagement is encouraged and pursued.

\section{CRediT author statement}

All authors contributed equally to this work.

\section{Declaration of Competing Interest}

The authors declare that they have no known competing financial interests or personal relationships that could have appeared to influence the work reported in this paper.

\section{Supplementary materials}

Supplementary material associated with this article can be found, in the online version, at doi:10.1016/j.respol.2020.104114.

\section{Appendix A. Search term combinations used for literature search}

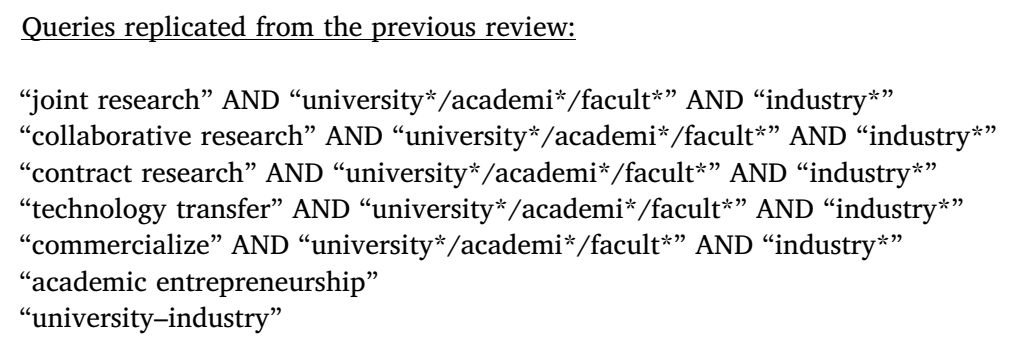

\section{New queries:}

"joint research"/"collaborative research"/"contract research"/“technology transfer" /commercializ* AND universit* AND social” "joint research"/"collaborative research"/"contract research"/“technology transfer" /commercializ* AND universit* AND societ* "joint research"/"collaborative research"/"contract research"/"technology transfer" /commercializ* AND universit* AND impact* "joint research"/"collaborative research"/"contract research"/"technology transfer" /commercializ* AND universit* AND open* sponsor* AND universit* AND industr*

\section{Appendix B. Tabular summary of articles reviewed}

\begin{tabular}{|c|c|c|c|c|c|}
\hline Article & Research Questions & Data & Method & Dep. Variables & Results \\
\hline $\begin{array}{l}\text { Abreu and Grinevich- } \\
\qquad \text { (2013) }\end{array}$ & $\begin{array}{l}\text { What are the determi- } \\
\text { nants of various types of } \\
\text { academic engagement? }\end{array}$ & $\begin{array}{l}\text { Survey of } 126,120 \text { aca- } \\
\text { demics from all UK } \\
\text { higher education institu- } \\
\text { tions }(n=22,556) 2005-8\end{array}$ & Regression & $\begin{array}{l}\text { Six 'entrepreneurial' ac- } \\
\text { tivities: licensing; spin- } \\
\text { outs; consultancy; con- } \\
\text { tract research; informal } \\
\text { advice; public lectures. }\end{array}$ & $\begin{array}{l}\text { Senior academics are } \\
\text { more likely to engage in } \\
\text { all types of entrepre- } \\
\text { neurial activities, parti- } \\
\text { cularly in contract re- } \\
\text { search and providing } \\
\text { informal advice. Female } \\
\text { academics are less likely } \\
\text { to be involved in entre- } \\
\text { preneurial activities, par- } \\
\text { ticularly consultancy and } \\
\text { contract research. } \\
\text { Academics working on } \\
\text { user-inspired or applied }\end{array}$ \\
\hline
\end{tabular}




$\begin{array}{ll}\text { Abreu and Grinevich- } & \text { What determines the } \\ \text { (2017) } & \text { gender gap in academic } \\ \text { entrepreneurship? }\end{array}$
entrepreneurship?
Survey of 126,120 aca-

demics from all UK

higher education institu-

tions $(n=22,556) 2005-8$
What are academics' and firms' motives for engaging in university-industry knowledge transfer?
Case studies in the context of the Faraday Partnership Initiative (UK)

Interviews with 46 researchers at National existing pers tionships shape academic engagement ("formation of knowledge linkages")? University of Central Buenos Aires 2013
Regression

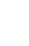

Qualitative

$\mathrm{n} / \mathrm{a}$

\section{Regression}

Aschhoff and Grimpe(2014)
How do social relationships influence an academic's decision to engage?
Survey of 3,360 German biotechnology academics enhanced with publication data $(n=355) 2004$ 2008
Banal-Estañol et al. (2015) How does collaboration with industry affect researchers' publication productivity?
Panel dataset for all researchers employed in the engineering departments of 40 UK universities $(\mathrm{n}=3,991)$ 1986-2007 Data on all spin-offs cre- Regression - matched ated in Italy between 2000 and 2007 by tenured academics $(\mathrm{n}=221) 2000-2007$

Regression sample
How does academic entrepreneurship affect academics' propensity to collaborate with other firms?
What influences aca-

Multi-source data on pademics' propensity to pa- tents, scientific articles tent and patenting quality and university funding in nanotechnology and received by academics in biotechnology? Quebec, Canada 19762005

Spinouts; patenting; licensing; consultancy; member of advisory boards; public lectures; contract research; providing informal advice; participating in exhibitions.

(2)


Bianchini et al. (2016)

How does publishing and consulting affect the quality of academics' teaching?
Unbalanced panel with 1,546 observations on 175 engineering professors at an Italian university
Regression and exploratory factor analysis
Dataset of 72 scientific publications disclosing 33 simultaneous discoveries. Some papers are authored by academic scientists only, others jointly by academic and industry scientists.

\section{Regression}

\section{3}

The count of scientific
papers that list the scientist as an author and cite their initial paper reporting the simultaneous discovery.

Number of publications; number of patents; number of standardisation committees in which the researcher is actively participating.

$\mathrm{n} / \mathrm{a}$

Interviews with 82 stake- Qualitative boration with multiple holders in 17 researchstakeholders initiated and collaboration projects in maintained? dates given.

quality, yet again this is U-shaped.

The consulting opportugiven by students (based nity effect on teaching quality is negative. Lower commitment to teaching is observed in professionoriented disciplines whose members tend to perform extra-academic engagements.

Academic scientists with industry collaborators produce more follow-on publications and fewer follow-on patents than academic scientists without industry collaborators. This effect is particularly salient when the research has important commercial implications and when the industry partner is an established firm.

Patenting is motivated by commercialisation ('gold'), while standardisation is motivated intrinsically ('ribbon').

Principal investigators play a lead role in establishing and managing collaboration with industry. The PI has to be a 'jack of all trades', taking on the roles of project manager, negotiator, resource acquirer as well as the traditional academic role of Ph.D. supervision and mentoring. Three strategies (topic alignment, proactive and selectiveness) are defined with respect to industry collaboration. Being more proactive and selective is associated with higher scientific output, contingent on the amount of funding obtained.

Academic engagement in the management disciplines facilitates better and more impactful research.
How do different types of Survey of 4,916 US aca-

Regression collaboration by academic scientists and endemics affect each other? gineers $(n=1,537) 2005$
Number of academic collaborators over the last year; number of collaborators.
Academic scientists working with industry collaborate more (with all types of collaborators) than those who do not. However, the volume of collaboration with industry is inversely correlated with the volume of academic-academic collaboration.

Degree of disclosure restrictions on publications resulting from any extramural sponsorship.
Scientists benefiting from industry sponsorship delay their publications and increase the secrecy around their research. Controlling for selection, adopting industry 


\section{Czarnitzki et al. (2015) How does extramural and Survey of 16,269 German Regression industry funding of aca- demic research affect academics' sharing beha- viour? \\ scientists in life sciences, natural sciences, engi- neering, and social sciences $(n=837) 2002$ - 2008}

D'Este et al. (2019)

De Fuentes and Dutrénit (2012)

Ding and Choi (2011)
What is the effect of interdisciplinary research on academic engagemen with industry?
Survey of 3,191 tenured Regression scientists covering all scientific fields. $\mathrm{n}=1,295$ 2011
Whether the academic had unsuccessfully requested any research results or research materials since 2002 from other scientists; whether the academic had denied others' access to their research results or materials since 2002 .

sponsorship more than doubles the expected probabilities of publication delay and secrecy. Receiving external funding in general does not affect sharing, but scientists with industry funding are twice as likely to deny requests for research access. Scientists who receive external funding of any kind are $50 \%$ more likely to be denied access to research materials by others.

Whether the scientist had Interdisciplinary research engaged at least once in has a positive influence three years in any form of on various types of acaU-I interaction (creating a demic engagement. The company, licensing of effect is stronger for acapatents or other forms of demic entrepreneurship IP rights, joint research and licensing compared projects with industry, to R\&D partnerships, and consulting services, con- contracts/consulting. tract research) organisations and firms collaborate, and what are the main types of knowledge transferred? in Mexico: (1) R\&D and product development managers in firms ( $\mathrm{n}=310$ firms); and, (2) PRO researchers $(n=385)$ 2008
Why do public research Two surveys carried out

Regression - multilevel Collaboration; channels of interaction (information \& training, R\&D projects \& consultancy, intellectual property rights, human resources); benefits from the interaction (strengthening capabilities based on R\&D, strengthening capabilitie based on innovation activities other than $R \& D$, improving quality).

Founding one or more for-profit companies; joining companies' scientific advisory boards. tists acting as company scientific advisors and those acting as company founders?
Case cohort design invol- Cox proportional having 5,143 life scientists zard model in a randomly drawn subcohort, augmented by

995 event cases (i.e. founders and SAB members) $1972-2002$
What impact do cooperative research centres have on the work of principal investigators? scientists affect both their ties and public research
How does temporary international mobility of scientists from universipropensity to engage in centres. $2005 \mathrm{~N}=958$ knowledge and technology transfer (KTT) and the locus of such transfer?

How does engaging in contract research with industry affect academic scientists' standing with their academic peers? of 34,647 scientist-year observations, derived from a sample of 9,502 academics employed at a
38 semi-structured interviews with senior scientists at the Centre for Research in Medical Devices (CÚRAM) in Ireland. 2017-18

Qualitative

a

Regression

Unbalanced panel dataset Regression UK university 2001-12
Whether the scientist's most recent research activity outside of Germany resulted in a transfer of technological knowledge or expertise to a firm in Germany and/or in the host country.

Count of grants awarded to each scientist.
Researchers without postgraduate degrees and those engaged in basic research and technology development are more

likely to connect with industry, compared to those performing applied research. Researchers in Biology \& Chemistry and Engineering tend to collaborate much more than those from Medicine \& Health Sciences. Scientists who become academic entrepreneurs are different from those who become companies' scientific advisors. Founding occurs earlier during a scientist's career than advising. Being a company's scientific advisor decreases the probability of becoming an academic founder. Involvement in cooperative research centre enhances senior scientists' research by providing opportunities for multidisciplinary collaboration, generating impact and acquiring resources, including network access. Mobile researchers are more productive in terms of publications. The existence of a strong and important research group abroad is an important pull factor for mobility.

Inverse U-shaped relationships between conferred industry contracts and peer evaluation: for lower levels of industry contract work, each marginal increase benefits a candidate's evaluation by their academic peers because appreciation from an external (industry) 


\author{
Fritsch and Krabel (2012) What informs the atti- \\ tudes of scientists to- \\ wards starting their ow \\ business or working in \\ private sector firm? \\ Survey of Max Planck \\ Society scientists \\ $(\mathrm{N}=7,808, \mathrm{n}=2,604)$ \\ 2007
}

Regression

(n)

Attractiveness of starting a business and attractiveness of work in the private sector.
Garcia et al. (2020)

How do long-term university-industry collaborations affect scientific productivity of research groups?

Goel and Göktepe-Hultén (2013)

Goel and Göktepe-Hultén(2018)

Gulbrandsen and Thune(2017)

Halilem et al. (2017)
To what extent do industry collaboration and consulting affect academics' patenting?

What determines scientists' decision to bypass the TTO? academic engagement and research performance?
Longitudinal database of Difference-in-differ- Number of articles pubuniversity-industry colla- ences, propensity score lished by each academic boration providing infor- matching (PSM) mation on 8,053 academic research groups in Brazil 2002-8

Survey of 7,808 Max Planck Society scientists $(\mathrm{n}=2,604) 2007$

\section{Survey of 7,808 Max}

Planck scientists in Germany $(n=2,500)$ 2007

Regression vention but did not disclose to TTO.

\section{Regression \\ Whether the scientist participated in a patent application or filed for a patent.}

\section{Survey of $80 \%$ of} Norwegian academics ( $n=4,400$, response rate $52.5 \%)$. No dates given. What is the effect of uni- Survey 3,908 Canadian versities' intellectual property right policies on patenting, spin-off creation, consulting and commercial agreements?
NSERC investigators of

university $(n=2,590)$

2007 reported patenting an in-

Whether the respondent
reported patenting an in-
vention but did not dis-
close to TTO.

$\begin{array}{ll}\text { Regression } & \begin{array}{l}\text { External engagement } \\ \text { (based on 18 items from } \\ \text { Abreu and } \\ \text { Grinevich (2013)). }\end{array} \\ \text { Regression - multilevel } & \begin{array}{l}\text { Formal commercialisa- } \\ \text { tion (patenting and } \\ \text { spinoff); informal com- } \\ \text { mercialisation (consul- } \\ \text { tancy services and com- } \\ \text { mercial agreements). }\end{array}\end{array}$

Annual count of publications for each academic.
What are the effects of public and private funding on the publication and patenting performance of academics?
Data on 807 tenured en- Regression gineering academics employed at 15 UK universities 1986-2007
Hughes and Kitson (2012) What is the breadth of knowledge exchange mechanisms used by academics across all
Survey of $125,000 \mathrm{UK}$ academics $(n=22,129)$ conducted by the Centre for Business Research (CBR); combined with
Regression

Extent of involvement in commercialisation (patenting, spin off, licensing) in the past three years, consultancy, and audience is read as indicative of ability. Yet, high levels of industry contract work are read as being indicative of the candidate's failure to conform to what is expected from an academic. The curvilinear effect is less accentuated for academics in disciplines that are close to industry, and for those with an excellent scientific performance record. For academics, research cooperation with industry has a positive effect on the assessed attractiveness of starting one's own business. Prior experience in $R \& D$ cooperation with private firms is positively related to the perceived attractiveness of working in the business sector.

Long-term collaboration with industry is positively (yet at a decreasing rate) associated with the scientific productivity (number of articles published) of academic research groups. Both collaboration and consulting have positive effects on patenting, with the magnitude for collaboration being larger. Different forms of academic engagement, including working in industry, industry cooperation and industry consulting, lead to more patenting but do so by bypassing the TTO. Non-academic experience is positively related to academic engagement; there is no effect on academic productivity. Higher levels of control (obligation to disclose and option to commercialise) by the university reduce the level of academic engagement. A higher royalty take (in terms of \% share) encourages academics to use informal routes to commercialisation, particularly consulting, rather than formal paths. Both public and private grants are positively associated with research productivity. However, industry funding negatively moderates the impact of public/non-profit grants. For commercially oriented research, however, there is a positive complementarity.

The spectrum of collaboration is varied and broad, with people-based mechanisms, the most frequent. This applies 
disciplines and different types of partners?

CBR survey of 22,000

businesses $(n=2,530)$

2005-8

Huyghe and Knockaert(2015)

Iorio et al. (2017)

Johnson et al. (2017)

Why do academics engage in formal or informal (e.g. collaborative research, contract research) commercialisation?

How does organisationa
culture and climate affe entrepreneurial inten-

Survey of 8,857 Swedish Regression tions in academia?

and German research scientists $(n=437) 2012$

What motivates academics to engage with industry?

Survey of 339 Italian academic inventors in Life Sciences, Chemistry, Maths, Physics, Engineering and Medicine $(\mathrm{n}=133) 2004$.

8

Survey of 7,065 science, Regression technology, engineering, and mathematics (STEM) academics at 14 Scottish universities $(n=818)$ 2014 high-intensity interactions (people-based, problem-solving and community-based). broadly to all disciplines. Academics collaborate with a broad spectrum of partners; most work with the public sector, fol-

lowed by third sector, finally businesses. For businesses, marketing and sales needs are more important than innovation as a motivation to work with universities. Universities' entrepre-

'Entrepreneurial' intentions (e.g. spin-off creation, intellectual property rights, and industryscience interaction).

Academic engagement index; knowledge transfer breadth (how many neurial communication and culture influences spin-off creation and IPR creation, but it has little effect on industry-science interaction (i.e. academic engagement).

Academic engagement, as depth, are correlated with channels are used for in- inventors' intent to access teraction with externals); funding and pursue proknowledge transfer depth social objectives. The in(intensity of use of various channels).

tent to learn was not found to be a significant predictor of all three outcomes.

Likelihood of engagement The stronger an acadein formal commercialisa- mic's chronic promotion tion activities within the focus (i.e. their attention next two years; likelihood is directed towards maxof engagement in in- imal goals) - the stronger formal commercialisation their intention to engage toral/postdoctoral reengage in informal com- activities within the next in informal commercial two years.

$\mathrm{n} / \mathrm{a}$

How do young scientist shape their career in the context of university entrepreneurialism?

Interviews with 24 doc-

Qualitative searchers and 16 professors from three UK universities 2006-07
Mixed methods

$\mathrm{n} / \mathrm{a}$ demics at five South

African universities $(n=2159) 2010$ and forms of acac engagement in different

Q
activities (e.g. academic engagement). However, the stronger an academic's chronic prevention focus (i.e. their attention is directed toward minimal goals) - the weaker their intention to mercial activities.

Engagement differs across types of South African universities. High academic reputation appears to be a barrier to engagement (descriptive data analysis).

Early career researchers involved in collaborative research are likely to experience tension with respect to pursuing their academic careers. They were found to "extend their investment" in their career by contributing to research collaboration with the expectation that their academic superiors may reciprocate in helping to advance their career.

What are scientists' ex-

36 individual interviews Mixed methods trinsic and intrinsic mo vations for pursuing and a survey of 3,100 scientists from five UK commercial activities and research universities academic engagement ? $\quad(n=734) .2006-07$
Whether the scientists are With regard to academic engaged in commercial engagement, scientists activities or collaborative are primarily motivated activities by professional recognition ('ribbon') as well as the intrinsic attraction of intellectual pursuit ('puzzle').

Publications; four indica- Collaboration by scientors of knowledge appli- tists with fellow scientists cation (preliminary facilitates knowledge 
application in university programmes at Israeli research programmes? universities $(n=268)$ 2007-8
What is the impact of university-industry collaboration on academic patenting?
Longitudinal data on aca- Regression demic, commercial and funding histories of 492 tenured engineering academics from ten UK universities for the period 1996 to 2007
Lawson et al. (2019)

Libaers (2014)
What are the differences in terms of academic engagement between foreign and domestic-born academics?
Large-scale survey of academics in the UK conducted by the Centre for Business Research (CBR) 2015. $\mathrm{N}=14,574$ from 151 different universities

What role does academics' geographic origin play in their interaction with private firms?

\section{Survey of academic} scientists at 150 most research-intensive universities in the US $(\mathrm{n}=1,466)$
Regression and semiparametric matching method

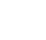
2004 search collaborations facilitate the commercialisation of universityoriginated technologies with a private firm?

Multi-source data (including survey) on population of 4,723 academic scientists in the sciences and engineering in the 150 most research-intensive US universities (n=1,795) 2004

Regression

National survey of aca-

Regression

How do the boundaryspanning behaviours of scientists engaged in emerging technology research affect their ability to obtain public grants?

Are there gender differences in academic patenting? demic scientists and engineers in Research I universities in the US $(n=880) 2006$

\footnotetext{
Survey of 3,677 academic Regression scientists randomly drawn from the US NETWISE network (biology, chemistry, physics, computer science, earth and atmospheric sciences/EAS, and electronic engineering) in 150 US research universities (Response rate 44\%) 2006-2010
}

studies, prototype, testing creation, and collaboraand commercialisation). tion with industry facilitates knowledge application (preliminary studies, prototype, testing, and commercialisation). However, in both cases, these effects turn negative when levels of collaboration becomes excessive.

Whether any patents Researchers with a large were filed by individual; share of research grants whether patents filed by from industry file more individuals were assigned patents. Small disseminato industry; whether pa- tion grants also have a tents filed by individuals positive effect. were assigned to university; whether any patents by individuals were granted; whether any patents were filed but not granted by individuals; number of filed patents by individuals; number of forward citations to patents filed by individuals. The number of different engagement activities reported by survey respondents (for intra-national and international engagement).

Binary measure of academic engagement: providing a company with research information; asking a company for research information; paid consulting for a company; co-authoring with industry; patenting with industry; commercialised with industry.

Percentage of researchrelated work time devoted to different categories of research collaboration (with own lab, with others in university, with foreigners, with other US universities).

Whether the respondent was conducting funded research in a recognised area of emerging technology.

Whether the scientist filed at least one patent application during the five-year period 20062010; count of an academic's patent applications in 2006-2010.
Foreign-born academics engage relatively more with international actors, and native-born relatively more with national actors. However, differences are modest and both groups engage more intra than internationally. Foreign-born academics are less likely to be consulted by firms, serve as a paid consultant to firms, or engage in commercialisation, relative to their US-born counterparts. But they are more likely to co-author scientific articles with firms.

Academic scientists adopting a university-industry collaboration strategy and spending more research time in such an arrangement are more likely involved in technology commercialisation with a private firm (however, this relationship is inversely Ushaped).

Interdisciplinarity is positively associated with obtaining public funding for emerging technologies. Industry patenting ties and commercialisation experience are positive for public grants. No gender gaps found. Collaboration with industry increases likelihood of patenting for female academic scientists. 
What partner attributes drive the matching of academic scientists and firms involved in collaborations?
Data on 447 faculty-industry contracts of a topranked US medical schoo (238 firms and 217 university scientists) 1994 2004
Regression - matched approach knowledge breadth and knowledge specialisation (for firms and scientists)
Perkmann et al. (2015)

How much of academics patenting, consulting and entrepreneurship is conducted independently from their university?
Panel dataset for full population of academics at Imperial College London. $\mathrm{N}=10,899$ 2001-13
Descriptive statistics $\quad \mathrm{n} / \mathrm{a}$ a

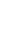

Ramos-Vielba et al. (2016) What motivates researchers to work with different types of partner organisations?
Survey of heads of reSpain $(n=851) 2011 \quad$ lysis in PSROs in ploratory factor ana-
Rentocchini et al. (2014) What is the relationship between engagement in consulting and the research performance of academic scientists?
Sample of 2,678 investigators at five Valencian universities 1999-2004
Regression
How do departmental characteristics and resources influence individual engagement with industry?
Survey of 4,916 tenuretrack and tenured STEM faculty at US research universities $(\mathrm{n}=1,795)$ 2000-2005
What factors shape the spatial pattern of university-industry collaboration?
Data on the industry number of connections with private firms made by professors at seven German institutions $(n=1,564) 2005$
Regression

The percentage of a researcher's time that they reported working with industry; a sum of the individual binary responses to questions about specific types of industry involvement; a weighted scale that accounts for the intensity of like likelihood of industry inthe involv

Number of private-sector collaboration partners each professor had on various spatial scales.

Extent to which an academic collaborates with industry (no The quality of academic human capital within a researcher's home department has a positive influence on individual engagement. Non-federal R\&D expenditures and direct industry funding positively increase the volvement.

Rather than mere spatial proximity, both institutional and social proximity (e.g. links to locations with $\mathrm{R} \& \mathrm{D}$ activities; locations of the universities from which researchers graduated; locations with academic start-ups founded by former colleagues and students) are positively associated with undertaking university-industry collaboration.

While access to financial and nonfinancial resources is the most im-
Regression
The publishing capabilities of firms and university scientists are complementary for innovation but substitutes for patents. More specialised individuals/firms create more value by teaming up with more knowledge-diversified partners.

Independent patenting amounts to $30 \%$ of overall academic patenting; independent consulting covers about three quarters of overall consulting, and independent entrepreneurship is about $90 \%$ of overall founding activity by academics at the studied university.

The intent to apply knowledge is the most important motivation for work with external partners (both firms and government). The intent to advance research is important, only for cooperation with government laboratories.

Engaging in consulting activities is negatively correlated with the average number of ISIpublications in the subsequent period in Natural and Exact Sciences and Engineering. No effect found for Medical

Sciences and Social Sciences and Humanities. portant factor spurring benefits and costs inform decisions? searchers at three larg

Italian universities, in nine different scientific 
Tartari and Salter (2015) Are there gender differences in the level and type of engagement with industry?

Dataset covering a popu- Regression

\section{Tartari et al. (2012) \\ What are the barriers faced by academics in their interactions with industry, and the factors that mitigate these bar- riers?} lation of 6,200 UK EPSRC investigators from 1992

to $2006(n=2,194)$

fields ( $n=731,34 \%$ response rate) 2008

Dataset covering a popu- Regression lation of 6,200 UK EPSRC investigators from 1992

to $2006(n=1,544)$
Tartari et al. (2014)

Thursby and Thursby(2011a)

Thursby and Thursby(2011b)
How do local social contexts influence individual academics' engagement with industry?

To what extent does patenting by academics in nano- and biotechnology reflect more collaborative behaviour compared to other fields?

How does involvement in licencing activity affect academics' research?
Dataset covering a popu- Regression lation of 6,200 UK EPSRC

investigators from 1992 to $2006(n=2,194)$

Sample of 1,319 patents Regression granted to 454 faculty inventors at eight US universities. 1994-1999
Individual academic engagement index (AEI).

Orientation barriers (six items related to the differences in timing, research choice and speed of the research process); transactional barriers (five items related to potential conflicts between university and industry over IP and university regulations).

Index covering a broade range of academic engagement forms.

Whether the patent falls into one of four classes: nanotechnology but not biotechnology; biotechnology but not nanotech nology; both nanotechnology and biotechnology; neither nanotechnology nor biotechnology.

Government funding; industry funding; number of publications; number of citations to those publications received throughout 2013. academic researchers to collaborate with industry, the perception that collaboration will limit a researcher's freedom is one of the main hindering factors.

Women engage less with industry than men. Higher prevalence of women in individuals' discipline reduces gender disparities; the same effect does not hold for the local work context.

The more a researcher has worked with industry, the less they will face "orientation barriers". The experience as an academic entrepreneur is negatively related to orientation barriers, while it is positively related to transaction barriers. Greater breadth (of collaboration channels) is also positively related to transaction barriers.

Academics' engagement with industry is informed by the behaviour of their departmental peers; the effects are stronger for junior faculty and weaker for star scientists.

Collaborative behaviour is stronger within nanoand biotechnology. The interpretation is that in

these fields where new breakthroughs are achieved, one can observe a greater degree of tacit knowledge.

Recent disclosure by faculty has seen a positive effect on industry and government funding, but if they disclose multiple times, the effect on government funding can be negative. Recent and repeated disclosures increase a faculty member's publication count and impact. The ability to attract funding and the rate of publication increases as the faculty member ages, but at a decreasing rate.

Whether the star scientist Mobile stars play an imadopted a specific re- portant role in creating gional knowledge transfer linkages between distant activity. areas. Stars maintain linkages to the science system at their former location. To a lesser extent, they also retain connections to firms located in the sending regions.

Whether the researcher had participated in formal standardisation activities between 2009 and 2010.
Researchers who publish in high quality journals are less likely to participate in standardisation. Researchers who publish in technical and industryoriented journals (non- 


\section{References}

Abreu, M., Grinevich, V., 2013. The nature of academic entrepreneurship in the UK: Widening the focus on entrepreneurial activities. Res. Policy 42, 408-422.

Abreu, M., Grinevich, V., 2017. Gender patterns in academic entrepreneurship. J. Tech. Transf.42 763-794.

Allen Consulting Group, 2012. The Economic, Social and Environmental Impacts of the Cooperative Research Centres Program. Innovation, Science, Research and Tertiary Education, Canberra Report to the Department of Industry.

Ankrah, S.N., Burgess, T.F., Grimshaw, P., Shaw, N.E., 2013. Asking both university and industry actors about their engagement in knowledge transfer: What single-group studies of motives omit. Technovation 33, 50-65.

Arza, V., Carattoli, M., 2017. Personal ties in university-industry linkages: A case-study from Argentina. J. Tech. Transf.42 814-840.

Aschhoff, B., Grimpe, C., 2014. Contemporaneous peer effects, career age and the in dustry involvement of academics in biotechnology. Res. Policy 43, 367-381.

Banal-Estañol, A., Jofre-Bonet, M., Lawson, C., 2015. The double-edged sword of industry collaboration: Evidence from engineering academics in the UK. Res. Policy 44 1160-1175.

Barbieri, E., Rubini, L., Pollio, C., Micozzi, A., 2018. What are the trade-offs of academic entrepreneurship? An investigation on the Italian case. J. Tech. Transf.43 198-221.

Beaudry, C., Kananian, R., 2013. Follow the (industry) money-The Impact of science networks and industry-to-university contracts on academic patenting in nanotechnology and biotechnology. Indust. Innov.20 241-260.

Bianchini, S., Lissoni, F., Pezzoni, M., Zirulia, L., 2016. The economics of research, consulting, and teaching quality: theory and evidence from a technical university. Econ. Innov. New Tech.25 668-691.

Bikard, M., Vakili, K., Teodoridis, F., 2019. When collaboration bridges institutions: The impact of university-industry collaboration on academic productivity. Org. Sci.30 426-445.

Blind, K., Pohlisch, J., Zi, A., 2018. Publishing, patenting, and standardization: Motives and barriers of scientists. Res. Policy 47, 1185-1197.

Boehm, D.N., Hogan, T., 2014. 'A jack of all trades': The role of PIs in the establishment and management of collaborative networks in scientific knowledge commercialisation. J. Tech. Transf.39 134-149.

Bonaccorsi, A., Piccaluga, A., 1994. A theoretical framework for the evaluation of university-industry relationships. R\&D Manage.24 229-247.

Bornmann, L., 2013. What is societal impact of research and how can it be assessed? A literature survey. J. Am. Soc. Inform. Sci. Tech.64 217-233.

Bozeman, B., Boardman, P.C., 2003. Managing the New Multipurpose, Multidiscipline University Research Centers: Institutional Innovation in the Academic Community. Washington: IBM Center for the Business of Government.

Bozeman, B., Gaughan, M., 2007. Impacts of grants and contracts on academic researchers' interactions with industry. Res. Policy 36, 694-707.

Callaert, J., Landoni, P., Van Looy, B., Verganti, R., 2015. Scientific yield from collaboration with industry: The relevance of researchers' strategic approaches. Res. Policy 44, 990-998.

Clark, B.Y., 2011. Influences and conflicts of federal policies in academic-industrial scientific collaboration. J. Tech. Transf.36 514-545.

Coberly, B.M., Gray, D.O., 2010. Cooperative research centers and faculty satisfaction: a multi-level predictive analysis. J. Tech. Transf.35 547-565.

Cohen, W.M., Nelson, R.R., Walsh, J.P., 2002. Links and impacts: The influence of public research on industrial R\&D. Manag. Sci.48 1.

Czarnitzki, D., Grimpe, C., Pellens, M., 2015. Access to research inputs: open science versus the entrepreneurial university. J. Tech. Transf.40 1050-1063.

Czarnitzki, D., Grimpe, C., Toole, A.A., 2015. Delay and secrecy: Does industry sponsorship jeopardize disclosure of academic research? Indust. Corp. Change 24, 251-279.

D’Este, P., Llopis, O., Rentocchini, F., Yegros, A., 2019. The relationship between interdisciplinarity and distinct modes of university-industry interaction. Res. Policy 48, 103799.

D'Este, P., Patel, P., 2007. University-industry linkages in the UK: What are the factors underlying the variety of interactions with industry? Res. Policy 36, 1295-1313.

Davey, T., Meerman, A., Muros, V.G., Orazbayeva, B., Baaken, T., 2018. The state of university-business cooperation in Europe. Publications Office of the European Union.

De Fuentes, C., Dutrénit, G., 2012. Best channels of academia-industry interaction for long-term benefit. Res. Policy 41, 1666-1682.

de Wit-de Vries, E., Dolfsma, W.A., van der Windt, H.J., Gerkema, M.P., 2019. Knowledge transfer in university-industry research partnerships: a review. J. Tech. Transf.44 1236-1255.

Ding, W., Choi, E., 2011. Divergent paths to commercial science: A comparison of scientists' founding and advising activities. Res. Policy 40, 69-80.

Dolan, B., Cunningham, J.A., Menter, M., McGregor, C., 2019. The role and function of cooperative research centers in entrepreneurial universities. Manag. Deci.57 3406-3425.

Edler, J., Fier, H., Grimpe, C., 2011. International scientist mobility and the locus of knowledge and technology transfer. Res. Policy 40, 791-805.
Fecher, B., Friesike, S., 2014. Open science: one term, five schools of thought. Opening science. Springer, pp. 17-47.

Fini, R., Jourdan, J., Perkmann, M., 2018. Social Valuation Across Multiple Audiences: The Interplay of Ability and Identity Judgments. Acad. Manag. J.61 2230-2264.

Foreman, P., Whetten, D.A., 2002. Members' identification with multiple-identity organizations. Org. Sci.13 618-635.

Franzoni, C., Sauermann, H., 2014. Crowd science: The organization of scientific research in open collaborative projects. Res. Policy 1, 1-20.

Friesike, S., Widenmayer, B., Gassmann, O., Schildhauer, T., 2015. Opening science: towards an agenda of open science in academia and industry. J. Tech. Transf.40 581-601.

Fritsch, M., Krabel, S., 2012. Ready to leave the ivory tower?: Academic scientists' appeal to work in the private sector. J. Tech. Transf.37 271-296.

Garcia, R., Araújo, V., Mascarini, S., Santos, E., Costa, A., 2020. How long-term university-industry collaboration shapes the academic productivity of research groups. Innov. Org. Manag.22 56-70.

Gaughan, M., Corley, E.A., 2010. Science faculty at US research universities: The impacts of university research center-affiliation and gender on industrial activities. Technovation 30, 215-222.

Goel, R.K., Göktepe-Hultén, D., 2013. Industrial interactions and academic patenting: Evidence from German scientists. Econ. Innov. New Tech.22 551-565.

Goel, R.K., Göktepe-Hultén, D., 2018. What drives academic patentees to bypass TTOs? Evidence from a large public research organisation. J. Tech. Transf.43 240-258.

Grau, F.X., Hall, B., Tandon, R., 2017. Higher education in the world 6. Towards a socially responsible university: Balancing the global with the local. Global University Network for Innovation, Girona.

Gulbrandsen, M., Thune, T., 2017. The effects of non-academic work experience on external interaction and research performance. J. Tech. Transf.42 795-813.

Haas, M.R., Park, S., 2010. To share or not to share?Professional norms, reference groups, and information withholding among life scientists. Org. Sci.21 873-891.

Halilem, N., Amara, N., Olmos-Peñuela, J., Mohiuddin, M., 2017. "To Own, or not to Own?" A multilevel analysis of intellectual property right policies' on academic entrepreneurship. Res. Policy 46, 1479-1489.

Hauser, H., 2014. Review of the Catapult network Recommendations on the future shape, scope and ambition of the programme. Department for Business Innovation \& Skills, London.

Hottenrott, H., Lawson, C., 2017. Fishing for complementarities: Research grants and research productivity. Int. J. Indust. Org.51 1-38.

Huang, K.G., Murray, F.E., 2009. Does patent strategy shape the long-run supply of public knowledge? Evidence from human genetics. Acad. Manag. J.52 1193-1221.

Hughes, A., Kitson, M., 2012. Pathways to impact and the strategic role of universities: new evidence on the breadth and depth of university knowledge exchange in the UK and the factors constraining its development. Cambridge J. Econ.36 723-750.

Hughes, A., Lawson, C., Salter, A., Kitson, M., Bullock, A., Hughes, R., 2016. The Changing State of Knowledge Exchange: UK Academic Interactions with External Organizations 2005-2015. NCUB, London.

Hughes, A., Martin, B., 2012. Enhancing impact. The value of public sector R\&D. NCUB, London.

Huyghe, A., Knockaert, M., 2015. The influence of organizational culture and climate on entrepreneurial intentions among research scientists. J. Tech. Transf.40 138-160.

Iorio, R., Labory, S., Rentocchini, F., 2017. The importance of pro-social behaviour for the breadth and depth of knowledge transfer activities: An analysis of Italian academic scientists. Res. Policy 46, 497-509.

Jensen, R., Thursby, M., 2001. Proofs and prototypes for sale: the licensing of university inventions. Am. Econ. Rev.91 240-259.

Johnson, M., Monsen, E.W., MacKenzie, N.G., 2017. Follow the leader or the pack? Regulatory focus and academic entrepreneurial intentions. J. Prod. Innov. Manag.34 $181-200$.

Jong, S., Slavova, K., 2014. When publications lead to products: The open science conundrum in new product development. Res. Policy 43, 645-654.

Kafouros, M., Wang, C., Piperopoulos, P., Zhang, M., 2015. Academic collaborations and firm innovation performance in China: The role of region-specific institutions. Res. Policy 44, 803-817.

Khazragui, H., Hudson, J., 2015. Measuring the benefits of university research: impact and the REF in the UK. Res. Evaluat.24 51-62.

Kongsted, H., Tartari, V., Cannito, D., Norn, M.T., Wohlert, J., 2017. University Researchers' Engagement with Industry, the Public Sector and Society: Results from a 2017. Survey of University Researchers in Denmark.

Kruss, G., Visser, M., 2017. Putting university-industry interaction into perspective: A differentiated view from inside South African universities. J. Tech. Transf.42 884-908.

Lam, A., 2011. What motivates academic scientists to engage in research commercialization:'Gold', 'ribbon'or 'puzzle'? Res. Policy 40, 1354-1368.

Lam, A., de Campos, A., 2015. 'Content to be sad'or 'runaway apprentice'?The psychological contract and career agency of young scientists in the entrepreneurial university. Hum. Relat.68 811-841.

Lavie, D., Drori, I., 2012. Collaborating for knowledge creation and application: The case of nanotechnology research programs. Org. Sci.23 704-724.

Lawson, C., 2013. Academic patenting: the importance of industry support. J. Tech. 
Transf.38 509-535.

Lawson, C., Hughes, A., Salter, A., Kitson, M., Bullock, A., Hughes, R., 2016. Knowledge Exchange in UK Universities: Results from a Panel of Academics 2005-2015. NCUB, London.

Lawson, C., Salter, A., Hughes, A., Kitson, M., 2019. Citizens of somewhere: Examining the geography of foreign and native-born academics' engagement with external actors. Res. Policy 48, 759-774.

Lee, Y.S., 1998. University-industry collaboration on technology transfer: Views from the ivory tower. Policy Stud. J.26 69-84.

Levin, S.G., Stephan, P.E., 1991. Research productivity over the life cycle: evidence for academic scientists. Am. Econ. Rev.81 114-132.

Libaers, D., 2014. Foreign-Born Academic Scientists and Their Interactions with Industry: Implications for University Technology Commercialization and Corporate Innovation Management. J. Prod. Innov. Manag.31 346-360.

Libaers, D., 2017. Time allocations across collaborations of academic scientists and their impact on efforts to commercialize novel technologies: is more always better? R\&D Manag.47 180-197.

Lin, M.-W., Bozeman, B., 2006. Researchers' industry experience and productivity in university-industry research centers: A "scientific and technical human capital" explanation. J. Tech. Transf.31 269-290.

Mansfield, E., 1995. Academic research underlying industrial innovations: sources, characteristics, and financing. Rev. Econ. Stat.1 55-65.

Martin, B.R., 2011. The Research Excellence Framework and the 'impact agenda': are we creating a Frankenstein monster? Res. Eval.20 247-254.

McDowell, G.R., 2001. Land-Grant Universities and Extension into the 21st Century: Renegotiating or Abandoning a Social Contract. ERIC.

McKelvey, M., Zaring, O., 2018. Co-delivery of social innovations: exploring the university's role in academic engagement with society. Indust. Innov.25 594-611.

Melkers, J., Xiao, F., 2012. Boundary-spanning in emerging technology research: Determinants of funding success for academic scientists. J. Tech. Transf.37 251-270.

Meng, Y., 2016. Collaboration patterns and patenting: Exploring gender distinctions. Res. Policy 45, 56-67.

Meyer-Krahmer, F., Schmoch, U., 1998. Science-based technologies: university-industry interactions in four fields. Res. Policy 27, 835-851.

Mindruta, D., 2013. Value creation in university-firm research collaborations: A matching approach. Strat. Manag. J.34 644-665.

Münch, R., 2014. Academic capitalism: Universities in the global struggle for excellence. Routledge.

Nosek, B.A., Alter, G., Banks, G.C., Borsboom, D., Bowman, S.D., Breckler, S.J., Buck, S., Chambers, C.D., Chin, G., Christensen, G., 2015. Promoting an open research culture. Science 348, 1422-1425.

OECD, 2005. The Measurement of Scientific and Technological Activities, Oslo Manual: Guidelines for Collecting and Interpreting Innovation Data. OECD Publishing, Paris.

Ovseiko, P.V., Pololi, L.H., Edmunds, L.D., Civian, J.T., Daly, M., Buchan, A.M., 2019. Creating a more supportive and inclusive university culture: a mixed-methods interdisciplinary comparative analysis of medical and social sciences at the University of Oxford. Interdiscipl. Sci. Rev.44 166-191.

Pache, A.-C., Santos, F., 2013. Embedded in hybrid contexts: How individuals in organizations respond to competing institutional logics, Institutional logics in action, part B. Emerald Group Publishing Limited.

Perkmann, M., Fini, R., Ross, J.-M., Salter, A., Silvestri, C., Tartari, V., 2015. Accounting for universities' impact: Using augmented data to measure academic engagement and commercialization by academic scientists. Res. Eval.24 380-391.

Perkmann, M., McKelvey, M., Phillips, N., 2019. Protecting scientists from Gordon Gekko: How organizations use hybrid spaces to engage with multiple institutional logics. Org. Sci.30 235-445.

Perkmann, M., Schildt, H., 2015. Open data partnerships between firms and universities: The role of boundary organizations. Res. Policy 44, 1133-1143.

Perkmann, M., Tartari, V., McKelvey, M., Autio, E., Broström, A., D’Este, P., Fini, R., Geuna, A., Grimaldi, R., Hughes, A., 2013. Academic engagement and commercialisation: A review of the literature on university-industry relations. Res. Policy 42,
$423-442$.

Ponomariov, B.L., 2008. Effects of university characteristics on scientists' interactions with the private sector: An exploratory assessment. J. Tech. Transf.33 485-503.

Ramos-Vielba, I., Sánchez-Barrioluengo, M., Woolley, R., 2016. Scientific research groups' cooperation with firms and government agencies: motivations and barriers. J. Tech. Transf.41 558-585.

Rentocchini, F., D’Este, P., Manjarrés-Henríquez, L., Grimaldi, R., 2014. The relationship between academic consulting and research performance: Evidence from five Spanish universities. Int. J. Indust. Org.32 70-83.

Ross, J.S., Krumholz, H.M., 2013. Ushering in a new era of open science through data sharing: the wall must come down. JAMA309 1355-1356.

Rüegg, W., 2004. A history of the university in Europe: Volume 3, universities in the nineteenth and early twentieth centuries (1800-1945). Cambridge University Press.

Scellato, G., Franzoni, C., Stephan, P., 2015. Migrant scientists and international networks. Res. Policy 44, 108-120.

Schaeffer, V., Öcalan-Özel, S., Pénin, J., 2020. The complementarities between forma and informal channels of university-industry knowledge transfer: A longitudinal approach. J. Tech. Transf.45 31-55.

Schartinger, D., Rammer, C., Fischer, M.M., Frohlich, J., 2002. Knowledge interactions between universities and inudstry in Austria: Sectoral patterns and determinants. Res. Policy 31, 303.

Schuelke-Leech, B.-A., 2013. Resources and research: An empirical study of the influence of departmental research resources on individual STEM researchers involvement with industry. Res. Policy 42, 1667-1678.

Slaughter, S., Leslie, L.L., 1997. Academic capitalism: Politics, policies, and the entrepreneurial university.

Slavtchev, V., 2013. Proximity and the transfer of academic knowledge: Evidence from the spatial pattern of industry collaborations of East German professors. Reg. Stud.47 686-702.

Tartari, V., Breschi, S., 2012. Set them free: scientists' evaluations of the benefits and costs of university-industry research collaboration. Indust. Corp. Change21 1117-1147.

Tartari, V., Perkmann, M., Salter, A., 2014. In good company: The influence of peers on industry engagement by academic scientists. Res. Policy 43, 1189-1203.

Tartari, V., Salter, A., 2015. The engagement gap: Exploring gender differences in University-Industry collaboration activities. Res. Policy 44, 1176-1191.

Tartari, V., Salter, A., D'Este, P., 2012. Crossing the Rubicon: exploring the factors that shape academics' perceptions of the barriers to working with industry. Cambridge J. Econ.36 655-677.

Tennent, J.A.R.; Baždarić, K.; Brassard, D.; Crick, T.; Dunleavy, D. J.; ...Yarkoni, T.;2020. A tale of two 'opens': intersections between Free and Open Source Software and Open Scholarship. https://doi.org/10.31235/osf.io/2kxq8.

Tennant, J.P., Waldner, F., Jacques, D.C., Masuzzo, P., Collister, L.B., Hartgerink, C., 2016. The academic, economic and societal impacts of Open Access: An evidencebased review. F1000Res.5 632.

Thursby, J., Thursby, M., 2011a. University-industry linkages in nanotechnology and biotechnology: evidence on collaborative patterns for new methods of inventing. J. Tech. Transf.36 605-623.

Thursby, J.G., Thursby, M.C., 2011b. Faculty participation in licensing: implications for research. Res. Policy 40, 20-29.

Tijssen, R.J., Yegros-Yegros, A., Winnink, J.J., 2016. University-industry R\&D linkage metrics: validity and applicability in world university rankings. Scientometrics 109, 677-696.

Trippl, M., 2013. Scientific mobility and knowledge transfer at the interregional and intraregional level. Reg. Stud.47 1653-1667.

Upton, S., Vallance, P., Goddard, J., 2014. From outcomes to process: Evidence for a new approach to research impact assessment. Res. Eval.23 352-365.

Van Looy, B., Callaert, J., Debackere, K., 2006. Publication and patent behavior of academic researchers: Conflicting, reinforcing or merely co-existing? Res. Policy 35, 596-608.

Zi, A., Blind, K., 2015. Researchers' participation in standardisation: A case study from a public research institute in Germany. J. Tech. Transf.40 346-360. 